This item was submitted to Loughborough's Research Repository by the author.

Items in Figshare are protected by copyright, with all rights reserved, unless otherwise indicated.

\title{
Validation of the Fiala multi-node thermophysiological model for UTCI application
}

PLEASE CITE THE PUBLISHED VERSION

http://dx.doi.org/10.1007/s00484-011-0450-5

PUBLISHER

Springer Verlag (@ ISB)

VERSION

AM (Accepted Manuscript)

LICENCE

CC BY-NC-ND 4.0

\section{REPOSITORY RECORD}

Psikuta, Agnes, Dusan Fiala, Gudrun Laschewski, Gerd Jendritzky, Mark Richards, Krzysztof Blazejczyk, Igor Mekjavic, Hannu Rintamaki, Richard de Dear, and George Havenith. 2019. "Validation of the Fiala Multi-node Thermophysiological Model for UTCI Application”. figshare. https://hdl.handle.net/2134/9319. 
This item was submitted to Loughborough's Institutional Repository (https://dspace.lboro.ac.uk/) by the author and is made available under the following Creative Commons Licence conditions.

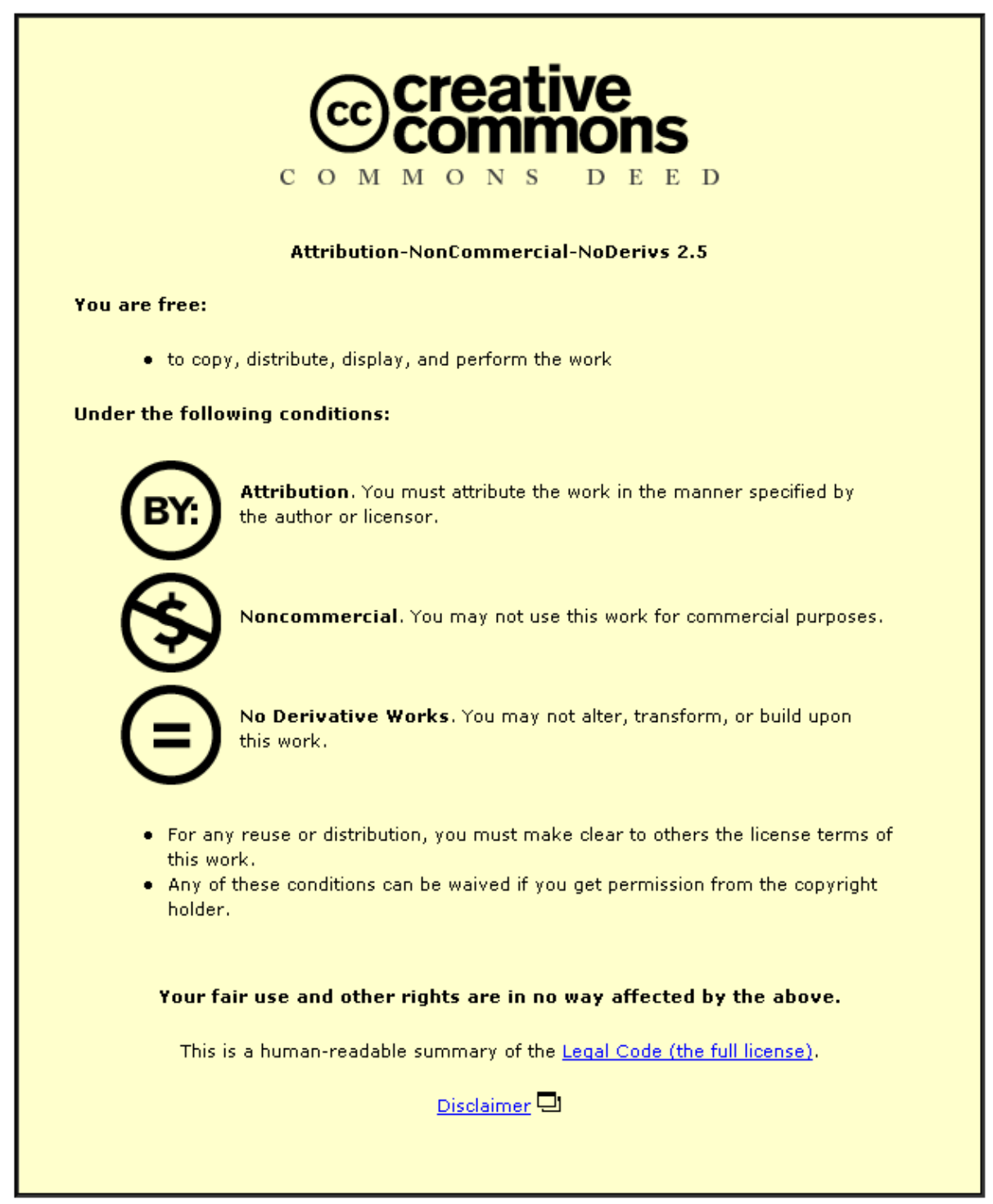

For the full text of this licence, please go to: http://creativecommons.org/licenses/by-nc-nd/2.5/ 


\section{Editorial Manager(tm) for International Journal of Biometeorology}

Manuscript Draft

Manuscript Number: IJBM-D-10-00162R1

Title: Validation of the Fiala multi-node thermophysiological model for UTCI application

Article Type: Original Research - Special Issue (UTCI)

Keywords: physiological model; physiological simulation

Corresponding Author: Agnes Psikuta, Ph.D.

Corresponding Author's Institution:

First Author: Agnes Psikuta, Ph.D.

Order of Authors: Agnes Psikuta, Ph.D.;Dusan Fiala, Ph.D.;Gudrun Laschewski, Ph.D.;Gerd Jendritzky, Ph.D.;Mark Richards, Ph.D.;Krzysztof Błażejczyk, Ph.D.;Igor Mekjavič, Ph.D.;Hannu Rintamäki, Ph.D.;Richard de Dear, Ph.D.;George Havenith, Ph.D.

Abstract: The important requirement that COST Action 730 demanded of the physiological model to be used for the Universal Thermal Climate Index was its capability of accurate simulation of the human thermophysiological responses across a wide range of relevant environmental conditions, such as conditions corresponding to the selection of all habitable climates and their seasonal changes, and transient conditions representing temporal variation of outdoor conditions.

In the first part of this study available heat budget/two-node models and multi-node thermophysiological models were evaluated by direct comparison over the wide spectrum of climatic conditions. The UTCI-Fiala model predicted most reliably the average human thermal response which was showed by least deviations from physiologically plausible responses when compared to other models. In the second part of the study, this model was, therefore, subjected to extensive validation using results of human subject experiments for a range of relevant (steady-state and transient) environmental conditions. The UTCI-Fiala multi-node model proved its ability to predict adequately the human physiological response for a variety of moderate and extreme conditions represented in the COST 730 database. The mean skin and core temperatures were predicted with average root-meansquare deviations of $1.35 \pm 1.00^{\circ} \mathrm{C}$ and $0.32 \pm 0.20^{\circ} \mathrm{C}$, respectively. 


\section{Validation of the Fiala multi-node thermophysiological model for UTCI application}

Agnes Psikuta $^{1)}$, Dusan Fiala ${ }^{2,3)}$, Gudrun Laschewski ${ }^{4)}$, Gerd Jendritzky ${ }^{5)}$, Mark Richards ${ }^{1,6)}$, Krzysztof Błażejczyk ${ }^{7)}$, Igor Mekjavič ${ }^{8)}$, Hannu Rintamäki ${ }^{9)}$, Richard de Dear ${ }^{10)}$, George Havenith ${ }^{11)}$

1) Empa, Laboratory for Physiology and Protection, Lerchenfeldstrasse 5, 9014 St. Gallen, Switzerland, +41 7127473 76, agnieszka.psikuta@empa.ch

2) ErgonSim-Comfort Energy Efficiency, Holderbuschweg 47, 70563 Stuttgart, Germany

3) IBBTE, University of Stuttgart, Keplerstraße 11, 70174 Stuttgart, Germany

4) Centre for Human-Biometeorological Research, Deutscher Wetterdienst, Stefan-Meier-Straße 4, 79104 Freiburg, Germany

${ }^{5)}$ Meteorological Institute, University of Freiburg, Werthmannstraße 10, 79085 Freiburg, Germany

6) humanikin GmbH, Grüner Baumweg 8, 9425 Thal, Switzerland

7) Institute of Geography and Spatial Organization, PAN, ul. Twarda 51/55, 00818 Warsaw, Poland

8) Jozef Stefan Institute, Jamova 39, 1000 Ljubljana, Slovenia

9) Finnish Institute of Occupational Health, Aapistie 1, 90220 Oulu, Finland

${ }^{10)}$ Faculty of Architecture, Design \& Planning, The University of Sydney, Wilkinson Building (G04), 148 City Road, NSW 2006, Sydney, Australia

11) Environmental Ergonomics Research Centre, Loughborough University, LE11 3TU, Loughborough, UK 


\begin{abstract}
The important requirement that COST Action 730 demanded of the physiological model to be used for the Universal Thermal Climate Index was its capability of accurate simulation of the human thermophysiological responses across a wide range of relevant environmental conditions, such as conditions corresponding to the selection of all habitable climates and their seasonal changes, and transient conditions representing temporal variation of outdoor conditions.

In the first part of this study available heat budget/two-node models and multi-node thermophysiological models were evaluated by direct comparison over the wide spectrum of climatic conditions. The UTCI-Fiala model predicted most reliably the average human thermal response which was showed by least deviations from physiologically plausible responses when compared to other models. In the second part of the study, this model was, therefore, subjected to extensive validation using results of human subject experiments for a range of relevant (steadystate and transient) environmental conditions. The UTCI-Fiala multi-node model proved its ability to predict adequately the human physiological response for a variety of moderate and extreme conditions represented in the COST 730 database. The mean skin and core temperatures were predicted with average root-mean-square deviations of $1.35 \pm 1.00{ }^{\circ} \mathrm{C}$ and $0.32 \pm 0.20^{\circ} \mathrm{C}$, respectively.
\end{abstract}

Keywords: physiological model, physiological simulation 


\section{Introduction}

Research on the prevention of, protection against, and treatment of thermal strain led to the development of the various mathematical models of human thermal physiology. The simulation of the human body evolved from a single homogenous cylinder into multi-layered cylinders of various sizes, thermophysical and physiological properties for individual body parts with applied blood circulation. The development of both the single-homogenous-cylinder approach and the advanced-multi-layer-structure approach was continued independently as socalled one or two-node models (Fanger 1970; Gagge et al. 1971; Osczevski 1995) and multi-node models (Fiala et al. 1999; Huizenga et al. 2001; Stolwijk et al. 1973; Tanabe et al. 2002; Wissler 1985).

Many of the models were developed for a specific purpose, for example, to predict physiological responses across a narrow range of comfort conditions. The two-node model for indoor applications (Gagge et al. 1971; Gagge et al. 1986), which was subsequently adapted for outdoor applications by Pickup and De Dear (1999) aimed at simulation of human thermal comfort response rather than detailed physiological processes. The Physiological Equivalent Temperature was developed to enable comparison of outdoor thermal conditions with human thermal experience indoors (Höppe 1984, 1999). Another suite of models simulated the human face exposed to wind chill (Bluestein and Zecher 1999; Osczevski 1995; Osczevski and Bluestein 2005; Shitzer 2006) or were specific to study individual differences in thermoregulation (Havenith 2001). The Stolwijk model developed for NASA (Stolwijk et al. 1973) is probably the most popular amongst the multi-node approaches and it forms the foundation of most contemporary simulation tools. Another influential model was developed by Wissler and used to model exposures to microgravity, cold water immersion and hyperbaria (Wissler 2003, 1985). The most recent models take advantage of vastly enhanced computational power to provide high resolution and sophisticated analyses of environmental heat exchange and associated physiological responses such as local skin temperatures, blood perfusion rates, heat fluxes, sweat rates, cardiac output, core temperature, and respiratory heat loss (Fiala et al. 1999, 2001; Huizenga et al. 2001; Tanabe et al. 2002). Nevertheless, the enhanced computational sophistication of these models has not been matched with larger 
and more detailed physiological observation databases for the purposes of model validation.

One of the most recent models, which was made available to the COST Action $730^{1}$ was the multi-node thermophysiological model of Fiala (Fiala et al. 1999, 2001, 2003, 2010). A special version of Fiala's multi-node model was set up for COST Action 730 and hereafter referred to as the UTCI-Fiala model. Following the intention of UTCI to provide a direction-independent assessment tool, the passive (heat transfer) system of the UTCI-Fiala model was configured as a symmetric model with identical physiological responses on the left and right extremities and spatial body sectors, thereby enabling a reduction of the number of body elements to twelve comprising 187 tissue nodes in total (compared to 342 nodes of the original model). Secondly, the short wave radiation absorbed at the surface of each anatomic element was calculated using local projected area factors for unknown body orientation derived from work of Kubaha et al. (2004). Further adjustments and extensions of the original model are described by Fiala et al. (2011) in this special issue.

The essential requirement that COST Action 730 demanded of the model to be used for the Universal Thermal Climate Index was its capability of accurate simulation of the human thermophysiological responses across a very wide range of thermal environmental conditions. As the index was intended for the assessment of the outdoor conditions, the applicable range of environmental conditions should correspond to the selection of all habitable climates and their seasonal changes. The physiological model should also be able to cope with transient conditions such as continuous variability of outdoor conditions. Therefore, the aim of this study was to evaluate available thermophysiological models by direct comparison and plausibility analysis. In the second stage, the selected model was validated for a range of relevant (steady-state and transient) environmental conditions using a number of human data sets collected from the literature and from laboratories participating in this project.

\footnotetext{
${ }^{1}$ COST Action 730 refers to a European Cooperation in Science and Technology Action number 730 to develop a Universal Thermal Climate Index (UTCI).
} 


\section{Model inter-comparisons}

This inter-model comparison study was conducted in order to gain an overview on the performance of simple, two-node heat budget models and advanced, multinode physiological models and provided useful information on the quality of the individual models. The models selected for this study are listed in Table 1. As the UTCI-Fiala model was finally selected to develop UTCI, the following presentations concentrate on direct comparisons of this model with other models used in this analysis.

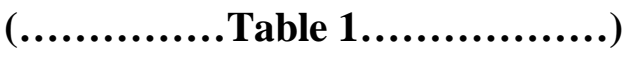

All listed models were run for a range of environmental conditions that included the ambient air temperature $\left(\mathrm{T}_{\mathrm{a}}\right)$ varying between $-35^{\circ} \mathrm{C}$ and $40^{\circ} \mathrm{C}$ (mean radiant temperature was set as equal to air temperature), air velocities between 1.1 and $17.6 \mathrm{~m} \cdot \mathrm{s}^{-1}$ at person level, and a relative humidity of $50 \%$. The simulations were conducted as individual two-hour exposures to steady environmental conditions and the subject was assumed to be walking at $1.1 \mathrm{~m} \cdot \mathrm{s}^{-1}$ (i.e. $\sim 135 \mathrm{~W} \cdot \mathrm{m}^{-2}$ or 2.3 met) and to be dressed in climatically appropriate clothing. Six clothing ensembles were specified ( $0.4-2.6$ clo $)$ to account for typical seasonal outfits. Clothing was modelled by applying individual items to the appropriate body parts of the multi-segmental models wherever such an option was available. The evaluation of model performance was done by comparing results of each model in Table 1 with the UTCI-Fiala model after two hours of exposure to the given conditions. The parameters under analysis included overall physiological responses, i.e. mean skin temperature $\left(\mathrm{T}_{\mathrm{sk}}\right)$, body core temperature $\left(\mathrm{T}_{\text {core }}\right)$, dry heat loss consisting of radiative and convective components $\left(\mathrm{Q}_{\text {dry }}\right)$, sweat evaporation from the skin $\left(E_{\mathrm{sk}}\right)$, the fraction of body surface area wet with sweat and referred to as skin wettedness (wet), heat generated by thermoregulatory shivering $\left(\mathrm{Q}_{\text {shiv }}\right)$, and heat loss by respiration $\left(\mathrm{Q}_{\text {resp }}\right)$, wherever available. The results were analysed visually in diagrams (examples in Figs. 1 and 2, and Figs. 17 and 18 in Electronic Supplemental Materials), and were summarised statistically by calculating the root-mean-squared deviations (rmsd), mean errors (bias) and coefficients of determination $\left(\mathrm{R}^{2}\right)$ (Table 2). Moreover, whenever predictions of a model were very similar to the predictions of the UTCI-Fiala model for most of the tested 
conditions and differed only at some conditions, the human subject data at these conditions were sought to arbitrate for the more physiologically plausible prediction.

\section{$(\ldots \ldots \ldots \ldots \ldots \ldots$ Figures 1 and $2 \ldots \ldots \ldots \ldots \ldots \ldots)$}

Generally, a higher level of agreement was obtained for multi-node models (the highest $\mathrm{R}^{2}$ for most of the physiological parameters studied, see Table 2) than for simple heat budget/two-node models involved in the analysis. This suggests that the UTCI should be based on an advanced multi-node model rather than one of the simpler models. Although the OUTSET model showed exceptionally high correlation with the UTCI-Fiala model amongst two-node models, the predicted skin temperatures varied remarkably (typically $>2{ }^{\circ} \mathrm{C}$, rmsd of $3 \cdot 2^{\circ} \mathrm{C}$ ).

Additionally, the core temperature predicted by OUTSET model for hot conditions disagreed with results of Moran et al. (1998) who reported $1.1^{\circ} \mathrm{C}$ lower core temperature measured in one hundred averagely fit subjects walking $(1.3 \mathrm{~m} / \mathrm{s})$ in environment at $40^{\circ} \mathrm{C}$ (and $0.1{ }^{\circ} \mathrm{C}$ lower than prediction of the UTCI-Fiala model). In particular, good agreement for the mean skin temperature (typically $<1{ }^{\circ} \mathrm{C}$ deviations, rmsd of $1.3^{\circ} \mathrm{C}$ ) was shown for the Tanabe and UTCI-Fiala models. On the other hand, in the cold, predictions of the body core temperature by the Tanabe and Berkeley multi-node models were strongly influenced by environmental conditions (much more than the UTCI-Fiala model). This, however, appeared to be in conflict with known experimental observations, for example, by Lind (1963) who showed that core temperature was independent on environmental temperature under cold to moderate conditions (differences between Tanabe model and reported data of $0.6^{\circ} \mathrm{C}$ and for the UTCI-Fiala model of $0.2^{\circ} \mathrm{C}$ on average). Further inter-model comparisons did show some remarkable deviations between individual models but no coherent picture regarding any systematic discrepancies between the selected simple heat budget and multi-node models.

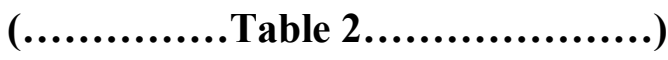


The predictions of the UTCI-Fiala model were also compared with the new Wind Chill Index (Osczevski and Bluestein 2005). For this purpose, the UTCI-Fiala model was used to predict facial skin temperatures and to calculate the Wind Chill Equivalent Temperature (WCET). WCET is defined as the air temperature of a reference environment that under calm wind conditions would cause the same facial heat loss to the environment as in the actual windy environment. Accordingly, the UTCI-Fiala model was used to simulate both the actual windy and the fictitious calm wind environments, whereby the temperature of the calm environment was varied in an iteration procedure to obtain the same (steady state) dry heat loss from the face as predicted for the windy environment $\left(\mathrm{q}_{\mathrm{dry}}\right.$ we $)$. The WCET could then be calculated for each time step using the dynamically predicted facial skin temperature $\left(\mathrm{T}_{\mathrm{sk}, \mathrm{f}}\right), \mathrm{q}_{\mathrm{dry}}$,we and the convective and radiative heat transfer coefficient for the calm environment $\left(\mathrm{h}_{\mathrm{c}+\mathrm{r}, \mathrm{ce}}\right)$ using the following equation:

$$
W C E T=T_{s, f}-\frac{q_{d r y, w e}}{h_{c+r, c e}}
$$

The examples of the results are shown in Fig. 3. The dynamic response predicted using the UTCI-Fiala model approached steady-state WCI values with discrepancies of less than $1{ }^{\circ} \mathrm{C}$, indicating a relatively good performance of the UTCI-Fiala model in comparison to other wind chill models that have been noted to differ by more than $10^{\circ} \mathrm{C}$ (Shitzer 2006).

\section{(..............Figure 3...........)}

Overall, the UTCI-Fiala model showed least deviations from physiologically plausible responses when compared to other models over the wide spectrum of climatic conditions considered in the study. It was also one of the few models and the only multi-node model which were made available to COST Action 730. In the next stage, this model was, therefore, subjected to extensive validation tests using results of human subject experiments. 


\section{Validation}

\section{The COST 730 database of physiological experiments}

A database of suitable experimental human data sets has been collected by the participants of the COST Action 730 and from the published literature. A unique opportunity arose from the fact that members of the modelling working group were able to provide comprehensive detailed experimental data from their laboratories. Therefore, the pool of validation data covered a wide range of environmental conditions, activity levels and clothing insulations. Moreover, it included exposures to diverse outdoor weather conditions including cold, hot dry or humid air, increased wind speeds, and solar and thermal radiation. The final database of experimental results collected for validation of the UTCI-Fiala model consisted of 59 exposures accompanied by descriptions of experimental protocol, environmental conditions and clothing parameters. The ranges of the experimental parameters of all exposures in the database are given in Table 3 in form of the maximum and minimum values.

\section{(............Table 3.......)}

One third of the total number of exposures (16 experiments) was conducted outdoors and the remaining two third (43 experiments) were carried out in climatic chambers. In addition, almost all experiments concerned transient conditions (52 out of 59 exposures). The distribution of the exposures in the database in relation to the ambient temperature and the metabolic rate is plotted in Fig. 4. "Only steady state" refers to exposures to constant environmental conditions for a period long enough for final steady-state physiological responses to be achieved (and recorded), "only transient" refers to exposures to changing environmental conditions and/or activity levels and "steady state and transient" refers to the combination of both types.

\section{(........Figure 4.............)}

The total number of subjects included in the validation experiments was 274 (18 females, 256 males). A description of the essential experimental conditions, 
number of subjects and number of repetitions for each exposure is provided in Table 4.

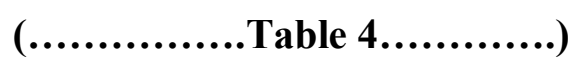

\section{Validation procedure}

Significant work involving three short-term scientific missions at various institutes and substantial data analysis has been carried out in order to validate the UTCI-Fiala model against a wide range of climatic conditions, physical exercise and clothing levels (Psikuta et al. 2006, 2007a, b).

Each experiment was simulated by accurately modelling the experimental boundary conditions and the exposed subjects. The description of the environmental conditions and activity levels for each exposure was provided either in form of constant values for a given period of time or as time-dependent values changing every minute within the exposure. The latter approach was used mostly for the outdoor exposures. The UTCI-Fiala model was able to accept these time-dependent input parameters allowing the simulation of situations including changing outdoor temperature and wind speeds, various cloudiness and solar radiation intensity, climbing and descending hills, or opening or removing clothes. The clothing thermal and evaporative properties for the validation study were determined using either direct measurements with thermal manikins or estimates according to ISO 9920 (2007) for those garments that were no longer available for direct measurement. The clothing parameters were adjusted for walking and wind effects based on equations by Holmér et al. (1999) and Havenith and Nilsson (2004, 2005) as they were summarised in ISO 9920 (2007) and described by Havenith at al. (IJB, 2011, this issue).

The simulations involved the modelling of each exposure individually according to the experimental protocol, the environmental conditions, and the clothing worn. In some cases, a detailed analysis of individual exposures was difficult or not possible due to various missing details such as information on the activity of the subjects prior to the actual exposure, sufficiently detailed description of the clothing worn, the exact locations and number of the measurements of local skin temperatures, details of climate conditions at the subjects' location in outdoor field studies (e.g. wind speed and solar radiation in areas of mixed landscapes 
with/out woodland or affected by topology), and sometimes indication of departure from the experimental protocol. In each of these cases and following a thorough data analysis and conversations with the experimenters/subjects involved in the trials, the most probable scenarios were chosen, simulated and evaluated.

Finally, the simulated and experimental results were compared graphically and statistically. The predicted quantities subjected to validation included physiological variables of interest which were available from the experiments, i.e. mean and local skin temperatures, body core temperatures (rectal, auditory canal), but also skin evaporation and metabolic rates (including shivering). Wherever possible, predicted results were compared with measured calorimetric and thermoregulatory responses (Psikuta et al. 2006, 2007a, b). However, most experiments in the database provided only skin and core temperatures. In the interests of consistent comparisons, these two physiological variables that govern the thermoregulatory and perceptual states of the human body were used for statistical evaluation throughout all exposures of the COST 730 database.

\section{Statistical analysis}

Root-mean-square deviations (rmsd) and bias of skin and core temperatures representing the essential physiological variables available for each experiment were calculated for all simulated exposures. The rmsd quantifies the average difference between a prediction and a measurement for a given exposure (Barlow 1989) and it is defined as:

$$
r m s d=\sqrt{\frac{\sum\left(x_{\text {measured }}-x_{\text {predicted }}\right)^{2}}{n}}
$$

where $x_{\text {measured }}$ is the measured value, $x_{\text {predicted }}$ is the predicted value, and $n$ is the number of data points in the exposure. The number of data points was defined as the number of simulations in the model inter-comparison and as the number of time points with given average value over all participating subjects. The bias quantifies the averaged error (i.e. literal difference between a prediction and a measurement) for a given exposure and it is defined as:

$$
\text { bias }=\frac{\sum\left(x_{\text {measured }}-x_{\text {predicted }}\right)}{n}
$$


In general, the rmsd is an indicator of the model precision, whereas the bias describes the model accuracy. The goodness of fit of the simulation results and the experimental data can be practically assessed by comparing rmsd values and the average standard deviation of the experimental data. The fit is considered as acceptable when rmsd is smaller than the standard deviation of the given data set. Ideally, the bias should equal or be close to zero to ensure unbiased model prediction.

\section{Results}

The validation results of all experiments are presented in form of rmsd for the mean skin and core temperatures together with details of each exposure in Table 4. The mean rmsd and bias, their standard deviations and medians for the mean skin and core temperatures for the entire COST 730 database of experiments are are plotted in Fig. 5. Exposures 42, 44 and 57-59 in Table 4 involving well-trained sportsmen were excluded from the statistical analysis since the UTCI and the UTCI-Fiala models are intended for simulation of an average human and the used version of the UTCI-Fiala model does not allow adjustments for fitness levels.

(......Figure 5.........)

\section{Discussion of validation results}

In general, the Fiala-UTCI multi-node model proved its ability to predict adequately the human physiological response for a variety of moderate and extreme conditions represented in the COST 730 database. The mean skin and core temperatures were predicted with average root-mean-square deviations of $1.35 \pm 1.00{ }^{\circ} \mathrm{C}$ and $0.32 \pm 0.20^{\circ} \mathrm{C}$ respectively that were slightly higher than typical standard deviations observed in subject studies of $1.0^{\circ} \mathrm{C}$ for the mean skin temperature and $0.2{ }^{\circ} \mathrm{C}$ for core temperature. The mean bias amounted 0.16 $\pm 1.40^{\circ} \mathrm{C}$ for the mean skin temperature and $0.10 \pm 0.27^{\circ} \mathrm{C}$ for the core temperature, which did not indicate any meaningful bias of the model. Also mean biases for exposures to cold conditions (below $0^{\circ} \mathrm{C}$ ) of $-0.37 \pm 1.83^{\circ} \mathrm{C}$ and $-0.01 \pm 0.19^{\circ} \mathrm{C}$ for the skin and core temperatures and to hot conditions (above $30^{\circ} \mathrm{C}$ ) of $0.81 \pm$ $0.43^{\circ} \mathrm{C}$ and $0.07 \pm 0.17^{\circ} \mathrm{C}$ respectively were lower than typical standard deviations of the experimental data. 
Moreover, the accuracy of the predictions by the model correlated with the number of subjects used in the experiment and with the number of details provided on experimental protocols and clothing. The larger the sample of subjects in an experiment, the better the agreement between measured and simulated results. Exposures 13-19, 22-24, 30-33 and 56 in Table 4 are examples of such studies with more than 8 subjects and the average rmsd for these experiments was $0.79 \pm 0.40^{\circ} \mathrm{C}$ (bias of $0.18 \pm 0.72^{\circ} \mathrm{C}$ ) for the mean skin temperature and $0.16 \pm 0.08^{\circ} \mathrm{C}$ (bias of $-0.04 \pm 0.12^{\circ} \mathrm{C}$ ) for the core temperature, which was better than the mean rmsd reported above. Secondly, the exposures that were accompanied by more detailed records of experimental procedure were usually associated with closer congruence between experimental and simulated results. Such examples include exposures 13-24 and 43, for which the average rmsd was $0.73 \pm 0.34^{\circ} \mathrm{C}$ (bias of $0.17 \pm 0.63^{\circ} \mathrm{C}$ ) for the mean skin temperature and $0.14 \pm 0.06^{\circ} \mathrm{C}$ (bias of $-0.04 \pm 0.09^{\circ} \mathrm{C}$ ) for the body core temperature.

\section{Simulation of clothing}

The UTCI-Fiala model offers a possibility of spatial and temporal variation in the thermal insulation across the body surface. It also permits variation in the clothing area factor and the evaporative resistance afforded by clothing garments. These parameters, however, could be affected by the conditions of the experiment (e.g. compression by wind). Therefore, it was crucial to know not only precise characteristics of the clothing but also all details of the experimental protocol. For exposures 11 and 12 in Table 4 (moderate/warm conditions), the simulation results showed poorer agreement with measured skin and core temperatures largely due to difficulties in accurately determining clothing evaporative resistance that varied from 6 to $24 \mathrm{~m}^{2} \cdot \mathrm{Pa} \cdot \mathrm{W}^{-1}$ when calculated by different methods (ISO 9920, 2007). Examples of simulated skin temperatures obtained under three different evaporative resistances of the clothing are plotted in Fig. 6, exp. 11 in Table 4.

\section{(...........Figure 6........)}

Using more detailed description of non-uniform clothing (separately for upper body and legs) improved the agreement with experimental data for simulations of all cold exposures (exp. 1-10, 13-18, 38-41 in Table 4) as indicated in Fig. 6, exp. 
9 in Table 4. Further improvement was obtained when the effect of walking and wind (compression of clothing, wind permeability and pumping effect decreasing thermal insulation and evaporative resistance) was considered according to equations by Holmér et al. (1999) and Havenith and Nilsson $(2004,2005)$ as showed in Fig. 6, exp. 18 in Table 4. For some field experiments, a detailed investigation into the exact course of the experiment (by contacting experimenters and subjects) explained some of the divergence between experiment and simulation. In all cases the departure from the experimental protocol was revealed, such as opening jackets during hiking (exp. 1-4 in Table 4, see Fig. 6 for exp. 2 in Table 4) or staying in a sheltered area during a windy period of the exposure (exp. 9 and 10 in Table 4). In the example of decreased insulation and evaporative resistance on the torso due to an open zip of the jacket shown in Fig. 6, exp. 2 in Table 4, both resistances were decreased (by theoretically estimated values of $0.0775 \mathrm{~m}^{2} \mathrm{~K} \cdot \mathrm{W}^{-1}$ and $20 \mathrm{~m}^{2} \mathrm{~Pa} \cdot \mathrm{W}^{-1}$ respectively) in the model settings on the anterior chest, abdomen and neck assuming that the outermost clothing layer was removed at these locations.

\section{Exposures to outdoor conditions}

Experiments 1-12 and 38-41 in Table 4 were conducted outdoors. The timedependent boundary conditions were used for the entire period of the exposure avoiding data averaging. The UTCI-Fiala model accepted the complex sets of input data and predicted physiological responses of the exposed subjects adequately. An example of such an exposure is shown in Fig. 7, exp. 1 in Table 4. In this experiment, subjects hiked in a hilly area under conditions in which the ambient temperature, the solar radiation and the metabolic rate varied during the exposure while the air humidity and the wind speed remained at more constant levels. The mean skin and core temperatures were predicted well within the standard deviation of the experimental data. It was also the case for local skin temperatures, although the predictions showed bigger discrepancies at some locations.

\section{(..........Figure $7 \ldots \ldots . . .$.}

Another whole-day exposure to winter outdoor conditions is plotted in Fig. 8, exp. 41 in Table 4. Initially, the subject spent less than one hour indoors (wearing 
lighter casual clothing), then put on outdoor clothing and hiked in hilly terrain on routes covered by hard snow at various metabolic rates alternated by short standing breaks. After returning indoors the subject took off the outdoor garments and remained seated, laying or doing light housework.

\section{(.............Figure 8.........)}

The simulations of the experiments shown in Fig. 8 demonstrated the applicability of the UTCI-Fiala model for the simulation of physiological responses to outdoor environments and transient thermal conditions when changing between indoor and outdoor environments.

\section{Exposures to cold wind}

In experiments 13-18 in Table 4, the subjects were exposed to the cold wind in a wind tunnel while wearing a military winter uniform. They were first preconditioned sitting either in a thermo-neutral or cool environment for $60 \mathrm{~min}$ and then faced a cold wind at various speeds and air temperature of $-10^{\circ} \mathrm{C}$. A comparison of measured and predicted physiological responses for experiment 17 in Table 4 is shown in Fig. 9. In general, the simulations reproduced adequately both the temporal trends and the absolute values of local and mean skin temperatures and core temperatures. Poorer agreement of skin temperatures was observed for posterior body parts (scapula, posterior thigh), probably because of the reduced wind compression of clothing in the posterior body areas (back in Fig. 9).

\section{(..................Figure 9..........)}

In these experiments, the facial skin temperatures were measured and, hence, provided an opportunity for testing the model against wind chill exposures. The temperatures of the exposed-to-wind and uncovered body parts (cheek, forehead) showed a good agreement with experimental data lying typically within one standard deviation. The analysis of these results, however, indicated also that for some instances the predicted face skin temperatures decreased slower during the initial 5-15 minutes of exposure to wind as compared to the measured data. Examples for wind velocities of 1 and $5 \mathrm{~m} \cdot \mathrm{s}^{-1}$ are shown in Fig. 10, exp. 14 and 15 in Table 4. 


\section{(...........Figure 10..........)}

\section{Exposures to extremely heterogeneous conditions}

In experiments 26-28 in Table 4, the semi-nude subjects exercised at constant activity level without resting while either the air and radiant temperatures or relative humidity varied at 20 minutes intervals. A comparison of measured and predicted physiological responses for experiment 26 in Table 4 is shown in Fig. 11. The simulations reproduced adequately both the temporal trends and the absolute values of mean skin and core temperatures, and sweat rate. A somewhat less accurate prediction of the absolute values of mean skin temperature could result from the adjustment of the algorithm for the calculation of the absorbed short wave radiation to use local projected area factors for unknown body orientation.

\section{(............Figure 11............)}

In experiments 34-37 in Table 4 the subjects exercised in an environment with a large difference between air and radiant temperatures and they put on light clothing after 80 minutes of exposure. Radiant surfaces were located in front of the subjects for most of the exposure time, while in the UTCI-Fiala model the radiation was simulated evenly from all directions. Despite this fact the agreement of the experimental and predicted data was statistically good, with rmsd for core temperatures approximating $0.12-0.36^{\circ} \mathrm{C}$ (bias between $0.07-0.33^{\circ} \mathrm{C}$ ) and 0.36 $1.09^{\circ} \mathrm{C}$ (bias between $0.24-1.01^{\circ} \mathrm{C}$ ) for mean skin temperatures. An example of such an exposure is shown in Fig. 12 (exp. 37 in Table 4).

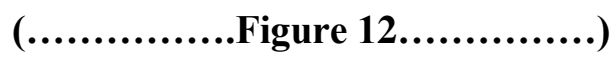

\section{Exposures to heat}

The COST 730 experimental database includes over 20 different exposures to hotdry or hot-humid thermal environments (Table 4). Experimental investigations of hot exposures often have focussed on studying the body core temperature and sweat rate as the critical physiological variable in such situations. A comparison of predicted and measured rectal temperatures for different hot exposures is shown in Fig. 13. The typical rmsd values for the body core temperature in this 
type of exposures were in the range of $0.20-0.25^{\circ} \mathrm{C}$ (although greater discrepancies resulted for experiments involving two or just one test subject).

Figure 13.............)

For warm and hot environments and in studies involving subjects exercising at higher activity levels involving greater sweat rates, the predicted skin temperatures sometimes tended to be lower than experimentally observed. An example of such an exposure is experiment 19 in Table 4, for which the model predicted decreasing skin temperature due to skin cooling by evaporation of sweat (Fig. 14). This effect, however, was not seen in the experimental data.

\section{(........Figure 14..........)}

The probable reason for such discrepancies was the impairment of skin cooling by sweat evaporation right at the place where the skin temperature sensor was taped onto the skin using semi-permeable tape. This hypothesis seems to be confirmed by infrared camera pictures of the front of a nude subject in parallel with regular skin temperature measurements as well as by numerical investigations (Fiala 1998). For example, in the experimental trials conducted at Empa (Jack 2010), the skin temperature of exercising subjects (exp. 44) was measured simultaneously using sensors taped onto the skin and an infrared camera. The results from the infrared temperature measurements on the chest and the thigh and from the corresponding taped-over temperature sensors are shown in Fig. 15 together with the predictions of the UTCI-Fiala model.

\section{(.........Figure 15...........)}

\section{Exercise}

Originally, the UTCI-Fiala model was validated for subjects of average fitness exercising at activity levels below 8 met. Although the model accepts metabolic rates up to 12 met, the predictions for activities higher than 8 met are based on extrapolation. During course of this validation, the model performed well for recreational athletes exercising at 9.2 met as indicated by the good fit of measured and simulated core temperatures for this experiment (Fig. 16, exp. 43 in Table 4). In experiment 42 in Table 4, professional sportsmen ran on a treadmill at high ambient temperature with metabolic rate of 12.1 met (Fig. 16, exp. 42 in Table 4). More efficient vasomotor and sweat responses by the professional sportsmen 
(Havenith 2001) compared to the UTCI-Fiala model (simulating an untrained average person) were probably the reason for the core temperature discrepancies seen in Figure 16. Other independent experiments seemed to confirm this observation, for example, experiments 57-59 in Table 4, in which the UTCI-Fiala model overestimated the core temperature by up to $0.6^{\circ} \mathrm{C}$ for well-trained individuals rowing in hot conditions. Although activity levels exceeding 3 met are irrelevant for the purposes of UTCI, the above examples revealed some limitations of the UTCI-Fiala model regarding predictions of physiological responses of well-trained exercising individuals. Experiments involving welltrained sportsmen (42, 44 and 57-59 in Table 4) were, therefore, excluded from the statistical analysis.

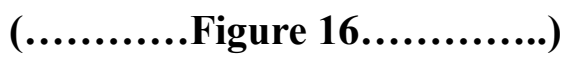

\section{Conclusions}

Summarizing, the COST 730 validation study included 59 exposures to cold, moderate, warm and heat-stress environmental conditions $\left(-13\right.$ to $50^{\circ} \mathrm{C}$ ambient temperatures, 0.1 to $22 \mathrm{~m} \cdot \mathrm{s}^{-1}$ wind speed, 0 to $600 \mathrm{~W} \cdot / \mathrm{m}^{-2}$ solar radiation), and a wide range of activity and clothing conditions ( 0.8 to 12 met, and 0.1 to 1.9 clo). This validation study focused predominantly on testing the UTCI-Fiala model against rather extreme conditions in terms of environmental conditions (ranging from cold and windy to very hot climates), activity level (hiking with a heavy load, heavy exercising on a bike ergometer) and clothing (ranging from bare-face exposed to cold wind to an impermeable chemical protection suit worn during exercise in heat). This wide variety of exposures represents a critical test of the UTCI-Fiala model; probably the most rigorous validation a physiological model has been subjected to thus far.

Within this range of the COST 730 database the UTCI-Fiala model reproduced the core temperature with an average rmsd of $0.32^{\circ} \mathrm{C} \pm 0.20^{\circ} \mathrm{C}$ and the mean skin temperature with a rmsd of $1.35^{\circ} \mathrm{C} \pm 1.00^{\circ} \mathrm{C}$. These ranges lie typically within the spread of the human physiological response data. The analyses revealed, inter alia, the importance of adequate modelling of clothing (using measured data), including effects such as the compression by wind, walking, clothing air permeability, and evaporative and thermal resistances. Therefore, the UTCI-Fiala 
model was extended to consider these effects by the adaptive clothing model as described by Havenith et al. (2011) in this special issue. The multi-node numerical model was able to adequately reproduce average thermal responses of untrained human subjects, across the wide range of conditions represented in the COST 730 experimental database. For well-trained individuals, however, discrepancies between simulated and measured data at high activity levels were observed. Other potential limitations included indications of a slower predicted response of facial skin temperatures to a sudden exposure to cold air, i.e. for about the first 10 minutes of the exposure (with subsequent good fit to measured facial skin temperatures following the initial period).

On the basis of the inter-comparisons and validations performed in this paper the UTCI-Fiala model appears to be a suitable prediction tool of the average human thermophysiological response across a wide range of environmental conditions. Therefore, the UTCI-Fiala model has been chosen to form the basis for the development of the Universal Thermal Climate Index. The reliable performance of the model in the exposures to outdoor weather conditions and to extremely heterogeneous environments is worth acknowledgement with respect to the later UTCI development and its future application. The need for the detailed description of the clothing revealed during this study initiated the development of the dedicated clothing model for the UTCI application.

\section{Acknowledgements}

The authors wish to thank COST Office and the Swiss State Secretariat for Education and Research (SBF/SER) for funding this work as part of COST Action 730 under project C06.0023, members of the WG1 of COST Action 730 for their comments and discussions, Dr. Emiel den Hartog from TNO for providing some data sets and hosting short term scientific mission in his laboratory, and to Dr. Veronika Meyer and Dr. René Rossi from Laboratory for Protection and Physiology at Empa for their editorial input.

References

Barlow RJ (1989) Different definitions of the standard deviation. In: Sandiford DJ, Mandl F, Phillips AC (eds) Statistics. A Guide to the Use of Statistical Methods in the Physical Sciences. John Wiley \& Sons Ltd., Chichester, pp 10-12

Błażejczyk K (1994) New climatological-and-physiological model of the human heat balance outdoor (MENEX) and its applications in bioclimatological studies in different scales. Zeszyty IgiPZ PAN 28:27-58 
Bluestein M, Zecher J (1999) A new approach to an accurate wind chill factor. Bull Amer Meteorol Soc 80 (9):1893-1899

Daanen HA, van Es EM, de Graaf JL (2006) Heat Strain and Gross Efficiency During Endurance Exercise after Lower, Upper, or Whole Body Precooling in the Heat. International Journal of Sports Medicine (5):379

Fanger PO (1970) Thermal Comfort. McGraw-Hill Book Co., New York

Fiala D, Lomas KJ, Stohrer M (1999) A computer model of human thermoregulation for a wide range of environmental conditions: the passive system. J Appl Physiol 87 (5):1957-1972

Fiala D, Lomas KJ, Stohrer M (2001) Computer prediction of human thermoregulatory and temperature responses to a wide range of environmental conditions. Int J Biometeorol 45 (3):143-159

Fiala D, Lomas KJ, Stohrer M (2003) First Principles Modelling of Thermal Sensation Responses in Steady-State and Transient Conditions. ASHRAE Transactions 109:179-186

Fiala D, Psikuta A, Jendritzky G, Paulke S, Nelson DA, van Marken Lichtenbelt WD, Frijns AJH (2010) Physiological modelling for technical, clinical and research applications. Front Biosci S2: 939-968 doi: 10.2741/s112

Fiala D, Havenith G, Bröde P, Kampmann B, Jendritzky G (2011) UTCI-Fiala multi-node model of human heat transfer and temperature regulation. Int J Biometeorol, Special Issue.

Gagge AP, Fobelets AP, Berglund PE (1986) A standard predictive index of human response to the thermal environment. ASHRAE Transactions 92:709-731

Gagge AP, Stolwijk JA, Nishi Y (1971) Effective Temperature Scale, Based on a Simple Model of Human Physiological Regulatory Response ASHRAE Journal 13 (1):58-\&

Gonzalez RR, McLellan TM, Withey WR, Chang SK, Pandolf KB (1997) Heat strain models applicable for protective clothing systems: comparison of core temperature response. $\mathrm{J}$ Appl Physiol 83 (3):1017-1032

Hardy JD, Stolwijk JA (1966) Partitional Calorimetric Studies of Man During Exposures to Thermal Transients. J Appl Physiol 21 (6):1799-\&

Haslam RA, Parsons KC (1988) Quantifying the Effects of Clothing for Models of Human Response to the Thermal Environment. Ergonomics 31 (12):1787-1806

Havenith G (2001) Individualized model of human thermoregulation for the simulation of heat stress response. J Appl Physiol 90 (5):1943-1954

Havenith G, Nilsson H (2004) Correction of clothing insulation for movement and wind effects, a meta-analysis. European Journal of Applied Physiology 92:636-640

Havenith G, Nilsson HO (2005) Correction of clothing insulation for movement and wind effects, a meta-analysis (vol 92, pg 636, 2004). European Journal of Applied Physiology 93 (4):506-506. doi:10.1007/s00421-004-1267-2

Havenith G, Fiala D, Błazejczyk K, Richards M, Broede P, Holmér I, Rintamaki H, Benshabat Y, Jendritzky G (2011) The UTCI-Clothing Model. Int J Biometeorol, Special Issue.

Holmer I, Nilsson H, Havenith G, Parsons K (1999) Clothing convective heat exchange - Proposal for improved prediction in standards and models. Ann Occup Hyg 43 (5):329-337

Höppe P (1984) Die Energiebilanz des Menschen. University Munich, Munich, Germany

Höppe P (1999) The physiological equivalent temperature - a universal index for the biometeorological assessment of the thermal environment. Int J Biometeorol 43 (2):71-75

Huizenga C, Zhang H, Arens E (2001) A model of human physiology and comfort for assessing complex thermal environments. Build Environ 36 (6):691-699

ISO7933 (1989) Hot environments - Analytical determination and interpretation of heat stress using calculation of required sweat rate.

ISO9920 (2007) Ergonomics of the thermal environment -- Estimation of thermal insulation and water vapour resistance of a clothing ensemble.

Jack A (2010) Einfluss hoch funktioneller Sporttextilien auf die Thermoregulation von Ausdauerathleten bei unterschiedlichen Umgebungstemperaturen. Bayreuth University, Bayreuth, PhD thesis.

Kubaha K, Fiala D, Toftum J, Taki AH (2004) Human projected area factors for detailed direct and diffuse solar radiation analysis. Int J Biometeorol 49 (2):113-129

Lind, AR (1963). A physiological criterion for setting thermal environmental limits for everyday work. J Appl Physiol 18: 51-56

Makinen T, Gavhed D, Holmer I, Rintamaki H (2000) Thermal responses to cold wind of thermoneutral and cooled subjects. European Journal of Applied Physiology 81 (5):397402

Moran DS, Shitzer A, Pandolf KB (1998) A physiological strain index to evaluate heat stress. American Journal of Physiology-Regulatory Integrative and Comparative Physiology 275 (1):R129-R134 
Osczevski R, Bluestein M (2005) The new wind chill equivalent temperature chart. Bull Amer Meteorol Soc 86 (10):1453-+. doi:10.1175/bams-86-10-1453

Osczevski RJ (1995) The basis of wind chill. Arctic 48 (4):372-382

Pickup J, De Dear R An Outdoor Thermal Comfort Index (OUT_SET*) - Part I - The Model and its Assumptions. In: de Dear R, Kalma, J., Oke, T., Auliciems, A. (ed) Biometeorology and Urban Climatology at the Turn of the Millenium, Sydney, 1999. pp 279-283

Psikuta A, Fiala D, Richards M (2006) Validation of the Fiala thermo-physiological model for COST 730 using human and clothing data. Part 1. STSM Scientific Report. Karlsruhe University, Karlsruhe

Psikuta A, Fiala D, Richards M (2007a) Further validation of the Fiala thermo-physiological model for COST 730 using human and clothing data. Part 2. STSM Scientific Report. Karlsruhe University, Karlsruhe

Psikuta A, Fiala D, Richards M (2007b) Further validation of the Fiala thermo-physiological model for COST 730 using human and clothing data. Part 3. STSM Scientific Report. TNO, Soesteberg

Shitzer A (2006) Wind-chill-equivalent temperatures: regarding the impact due to the variability of the environmental convective heat transfer coefficient. Int J Biometeorol 50 (4):224-232. doi:10.1007/s00484-005-0011-x

Stolwijk JA, Nadel ER, Wenger CB, Roberts MF (1973) Development and Application of a Mathematical - Model of Human Thermoregulation Archives des Sciences Physiologiques 27 (3):A303-A310

Tanabe S, Kobayashi K, Nakano J, Ozeki Y, Konishi M (2002) Evaluation of thermal comfort using combined multi-node thermoregulation $(65 \mathrm{MN})$ and radiation models and computational fluid dynamics (CFD). Energy Build 34 (6):637-646

Wissler EH (1985) Mathematical simulation of human thermal behaviour using whole body models. In: Shitzer A, Eberhart RC (eds) Heat transfer in Medicine and Biology. Analysis and Applications, vol 1. Plenum Press, New York and London, pp 325-374

Wissler EH (2003) Probability of survival during accidental immersion in cold water. Aviation Space and Environmental Medicine 74 (1):47-55 
Table 1 List of models used in inter-model comparison study

\begin{tabular}{|l|c|c|l|}
\hline Model name & Abbreviation & Model type & \multicolumn{1}{|c|}{ Reference } \\
\hline $\begin{array}{l}\text { Munich Energy Balance } \\
\text { Man-Environmental } \\
\text { Heat Exchange }\end{array}$ & MEMI & two-node & (Höppe 1999, 1984) \\
\hline Required Sweat Rate & RSR & two-node & ISO 7933:1989 \\
\hline $\begin{array}{l}\text { Outdoor Standard } \\
\text { Effective Temperature }\end{array}$ & OUTSET & two-node & $\begin{array}{l}\text { Pickup and De Dear } \\
\text { (Gagge et al. 1986; }\end{array}$ \\
\hline UTCI-Fiala & UTCI-Fiala model & multi-node & (Fiala et al. 1999, 2001) \\
\hline Waseda University & Tanabe model & multi-node & (Tanabe et al. 2002) \\
\hline $\begin{array}{l}\text { University of California } \\
\text { Berkeley }\end{array}$ & Berkeley model & multi-node & (Huizenga et al. 2001) \\
\hline Wind Chill Index & WCI & two-node & $\begin{array}{l}\text { (Osczevski and } \\
\text { Bluestein 2005) }\end{array}$ \\
\hline
\end{tabular}

Table 2 The average difference between individual models and the UTCI-Fiala model expressed as root mean square deviations (rmsd), mean errors (bias) and coefficients of determination $\left(\mathrm{R}^{2}\right)$ obtained from model inter-comparison

\begin{tabular}{|c|c|c|c|c|c|c|c|c|c|}
\hline \multirow{2}{*}{ Model } & \multirow{2}{*}{$\begin{array}{l}\text { Number of } \\
\text { simulations }\end{array}$} & \multirow{2}{*}{$\begin{array}{l}\text { Statistical } \\
\text { parameter }\end{array}$} & $\mathrm{T}_{\mathrm{sk}}$ & $\mathrm{T}_{\text {core }}$ & $\mathrm{Q}_{\text {dry }}$ & $\mathrm{E}_{\mathrm{sk}}$ & wet & $Q_{\text {shiv }}$ & $\mathrm{Q}_{\text {resp }}$ \\
\hline & & & ${ }^{\circ} \mathrm{C}$ & ${ }^{\circ} \mathrm{C}$ & $\mathrm{W} \cdot \mathrm{m}^{-2}$ & $\mathrm{~W} \cdot \mathrm{m}^{-2}$ & - & $\mathrm{W} \cdot \mathrm{m}^{-2}$ & $\mathrm{~W} \cdot \mathrm{m}^{-2}$ \\
\hline \multirow[b]{3}{*}{ MEMI } & \multirow{3}{*}{36} & $\mathrm{rmsd}$ & 7.3 & 4.0 & 79.8 & 48.3 & 0.1 & - & 12.7 \\
\hline & & bias & 4.3 & 2.1 & -66.3 & -15.2 & 0.1 & - & 5.5 \\
\hline & & $\mathrm{R}^{2}$ & 0.387 & 0.039 & 0.783 & 0.918 & 0.433 & - & 0.542 \\
\hline \multirow[b]{3}{*}{ Menex } & \multirow{3}{*}{70} & rmsd & 2.5 & - & - & - & - & - & - \\
\hline & & bias & 1.2 & - & - & - & - & - & - \\
\hline & & $\mathrm{R}^{2}$ & 0.707 & - & - & - & - & - & - \\
\hline \multirow[b]{3}{*}{ RSR } & \multirow{3}{*}{18} & rmsd & 5.1 & - & 54.4 & 67.5 & 0.3 & - & 2.6 \\
\hline & & bias & 3.3 & - & 33.8 & 44.3 & 0.1 & - & -1.5 \\
\hline & & $\mathrm{R}^{2}$ & 0.147 & - & 0.640 & 0.600 & 0.861 & - & 0.994 \\
\hline \multirow[b]{3}{*}{ SET } & \multirow{3}{*}{90} & $\mathrm{rmsd}$ & 3.2 & 0.5 & 16.8 & 10.8 & 0.1 & 33.7 & 8.8 \\
\hline & & bias & -2.3 & 0.2 & -1.8 & 2.7 & 0.0 & 19.0 & 6.5 \\
\hline & & $\mathrm{R}^{2}$ & 0.846 & 0.411 & 0.963 & 0.949 & 0.806 & - & 0.845 \\
\hline \multirow[b]{3}{*}{ Tanabe } & \multirow{3}{*}{180} & $\mathrm{rmsd}$ & 1.3 & 0.5 & 44.5 & 15.9 & 0.1 & 18.1 & 4.9 \\
\hline & & bias & -0.9 & 0.4 & 39.7 & 10.6 & 0.0 & 6.2 & 3.2 \\
\hline & & $\mathrm{R}^{2}$ & 0.935 & 0.284 & 0.870 & 0.961 & 0.816 & 0.639 & 0.867 \\
\hline \multirow{3}{*}{$\begin{array}{c}\text { UC } \\
\text { Berkley }\end{array}$} & \multirow{3}{*}{18} & rmsd & 3.2 & 1.1 & - & 8.4 & 0.2 & - & - \\
\hline & & bias & -2.4 & 1.1 & - & -2.7 & -0.1 & - & - \\
\hline & & $\mathrm{R}^{2}$ & 0.979 & 0.358 & - & 0.999 & 0.864 & - & - \\
\hline
\end{tabular}


Table 3 Maximum and minimum values of parameters in the database of COST 730

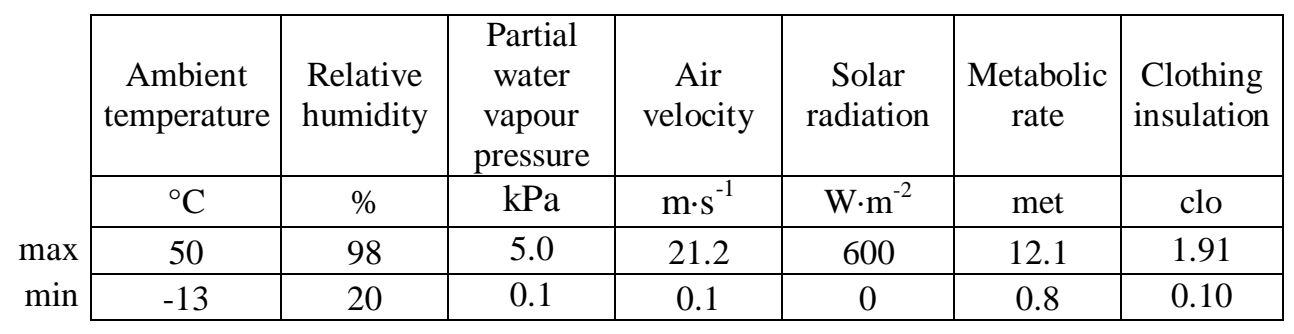


Table 4 General description and root mean square deviations (rmsd) and mean deviations (bias) of all experiments of the COST 730 database for the validation study. $R_{c l}$ and $R_{\text {ecl }}$ are clothing intrinsic thermal and evaporative resistances and $R_{t}$ is clothing total evaporative resistance.

Extended version of this table is to be found in Electronic Supplemental Materials.

\begin{tabular}{|c|c|c|c|c|c|c|c|c|c|c|c|c|c|c|c|}
\hline \multirow{3}{*}{ No. } & \multirow[b]{2}{*}{ Duration } & \multicolumn{5}{|c|}{ Environmental parameters } & \multicolumn{2}{|c|}{ Subjects } & \multirow[b]{2}{*}{$\mathbf{R c l} / \mathbf{R t}$} & \multirow[b]{2}{*}{ Recl } & \multicolumn{2}{|c|}{ rmsd } & \multicolumn{2}{|c|}{ bias } & \multirow{3}{*}{ Source of data } \\
\hline & & Air temp. & \begin{tabular}{|l} 
Radiant \\
temp.
\end{tabular} & $\begin{array}{l}\text { Relative } \\
\text { humidity }\end{array}$ & \begin{tabular}{|c|} 
Air \\
velocity
\end{tabular} & \begin{tabular}{|c|} 
Solar \\
radiation
\end{tabular} & $\begin{array}{c}\text { Metabolic } \\
\text { rate }\end{array}$ & Number & & & Tsk & Tcore & Tsk & Tcore & \\
\hline & $\min$ & ${ }^{\circ} \mathrm{C}$ & ${ }^{\circ} \mathrm{C}$ & $\% / \mathrm{kPa}$ & $\mathrm{m} / \mathrm{s}$ & $\mathrm{W} / \mathrm{m}^{2}$ & met & \begin{tabular}{|l}
$\begin{array}{l}\text { males/ } \\
\text { females }\end{array}$ \\
\end{tabular} & clo & $\mathrm{m}^{2} \mathrm{kPa} / \mathrm{W}$ & ${ }^{\circ} \mathrm{C}$ & ${ }^{\circ} \mathrm{C}$ & ${ }^{\circ} \mathrm{C}$ & ${ }^{\circ} \mathrm{C}$ & \\
\hline \multirow{12}{*}{\begin{tabular}{|c|}
1 \\
2 \\
3 \\
4 \\
5 \\
6 \\
7 \\
8 \\
9 \\
10 \\
11 \\
12 \\
\end{tabular}} & \multirow{12}{*}{180} & 8 & - & & & 48 & & & & & & & & & \multirow{12}{*}{$\begin{array}{l}\text { unpublished from I.Mekjavic, } \\
\text { Josef Stefan Institute in } \\
\text { Ljubljana, Slovenia }\end{array}$} \\
\hline & & $\frac{8}{0}$ & $\div$ & $48 \%$ & 0.10 & $\frac{48}{134}$ & $\begin{array}{r}4.0 \\
46\end{array}$ & $0 / 6$ & \multirow{2}{*}{$1.40 / 1.83$} & \multirow{2}{*}{0.03} & 0.64 & 0.31 & 0.31 & 0.03 & \\
\hline & & -4 & - & $77 \%$ & 0.10 & 138 & 4.9 & $1 / 2$ & & & 0.81 & $\begin{array}{l}0.38 \\
0.52 \\
\end{array}$ & $\frac{-0.75}{0.40}-x-3 x-10$ & $\frac{-0.22}{-0.42}$ & \\
\hline & & 6 & - & $61 \%$ & 0.09 & 67 & 1.5 & $0 / 9$ & \multirow{3}{*}{$1.40 / 1.83$} & \multirow{3}{*}{0.037} & 0.53 & 0.30 & 0.03 & 0.29 & \\
\hline & & 0 & - & $63 \%$ & 0.18 & 140 & 1.9 & $10 / 0$ & & & 0.50 & 0.18 & -0.05 & -0.04 & \\
\hline & & -6 & - & $88 \%$ & 0.30 & 149 & 1.7 & $2 / 0$ & & & 0.91 & 0.38 & -0.57 & 0.27 & \\
\hline & & -13 & - & $61 \%$ & 21.1 & 55 & $5.3(2.5)$ & $1 / 0$ & \multirow[b]{2}{*}{$1.40 / 1.83$} & \multirow[b]{2}{*}{0.037} & 1.47 & 0.75 & -1.02 & 0.17 & \\
\hline & & -3 & - & $77 \%$ & 21.2 & 65 & 3.8 & $6 / 0$ & & & 2.23 & 0.28 & 2.08 & -0.16 & \\
\hline & & 0 & - & $82 \%$ & 18.0 & 11 & 1.6 & $4 / 0$ & \multirow{2}{*}{$1.91 / 2.31$} & \multirow{2}{*}{0.064} & 0.43 & 0.26 & -0.26 & 0.24 & \\
\hline & & -8 & - & $54 \%$ & 20.4 & 14 & 2.9 & $4 / 0$ & & & 0.80 & 0.28 & 0.61 & -0.13 & \\
\hline & & 22 & - & $71 \%$ & 0.30 & 57 & 4.3 & $6 / 0$ & $0.84 / 128$ & $0.024-$ & 2.58 & 0.85 & 2.45 & -0.48 & \\
\hline & & 24 & - & $57 \%$ & 0.41 & 109 & 4.2 & $3 / 0$ & $0.84 / 1.28$ & 0.006 & 2.23 & 0.52 & 2.12 & -0.27 & \\
\hline 13 & & & & - & $0.2 / 0.2$ & - & & $8 / 0$ & & & 0.39 & 17 & -0.09 & & \\
\hline 14 & & $20 /-10$ & & - & $0.2 / 1.0$ & - & $1.0 / 1.2$ & $8 / 0$ & $1.2 / 1.88$ & 0.02 & 0.53 & 0.17 & 0.37 & $\frac{-0.12}{-0.02}$ & Makinen, Gavhed et al. 2000 \\
\hline 15 & son & & & - & $0.2 / 5.0$ & - & & $8 / 0$ & & & 0.66 & 0.14 & 0.45 & -0.06 & and unpublished from \\
\hline 16 & $60 / 30$ & & $\sim=\mathrm{Ta}$ & - & $0.2 / 0.2$ & - & & $8 / 0$ & & & 0.78 & 0.15 & -0.74 & -0.02 & H.Rintamäki, Finnish Institute of \\
\hline 17 & & $-5 /-10$ & & - & $0.2 / 1.0$ & - & $1.0 / 1.2$ & $8 / 0$ & 1.88 & 0.02 & 0.53 & 0.11 & -0.36 & -0.02 & \\
\hline 18 & & & & - & 0.225 .0 & - & & $8 / 0$ & & & 0.72 & 0.21 & -0.35 & -0.08 & \\
\hline & & & & & & & & & & & & & & & \\
\hline 19 & $50 / 50 / 30$ & 30 & $\sim=\mathrm{Ta}$ & $30 \%$ & 0.1 & - & 2.21/3.59/0.98 & $11 / 0$ & 0.1 & 0.013 & 1.59 & 0.07 & 1.42 & -0.01 & $\begin{array}{l}\text { Chappuis, Pittet et al. } 1976 \text { in } \\
\text { Haslam and Parsons } 1988\end{array}$ \\
\hline & & & & & & & & & & & & & & & \\
\hline 20 & $45 / 45$ & 49.5 & $\sim=\mathrm{Ta}$ & $32 \%$ & 0.1 & - & $1.0 / 4.42$ & $5 / 0$ & 0.1 & 0.013 & 0.68 & 0.23 & 0.59 & -0.21 & \begin{tabular}{|} 
Kobayashi, Horvath et al. 1980 \\
in Haslam and Parsons 1988
\end{tabular} \\
\hline 21 & $60 / 120 / 60$ & $43 / 17 / 43$ & $\sim=\mathrm{Ta}$ & $30 \%$ & 0.12 & - & 1.0 & $3 / 0$ & 0.1 & 0.013 & 0.51 & 0.17 & -0.11 & 0.13 & Hardy and Stolwijk 1966 \\
\hline & & & & & & & & & & & & & & & \\
\hline$\frac{22}{23}$ & 100 & 35 & $\sim=\mathrm{Ta}$ & $50 \%$ & 1.0 & . & 3.75 & $10 / 0$ & 1.69 & 0.100 & - & 0.06 & - & -0.01 & Gonzalez, McLellan et al. 1997 \\
\hline & & & & & & & & & & & & & & & \\
\hline 24 & 120 & 40 & $\sim=\mathrm{Ta}$ & $40 \%$ & 0.2 & - & 3.35 & $100 / 0$ & 0.1 & 0.013 & - & 0.12 & - & 0.02 & Moran, Shitzer et al. 1998 \\
\hline 25 & 170 & 28 & $\sim=\mathrm{Ta}$ & $50 \%$ & 0.1 & - & $1.0 / 3.9$ & $6 / 0$ & 0.1 & 0.013 & & 0.10 & & -0.07 & \\
\hline 26 & & 28 & $\sim=$ & & 0 & - & ...10. & $6 / 0$ & & & 1.20 & 0. & 1.03 & & \\
\hline 27 & & $23 / 50$ & $\sim=\mathrm{Ta}$ & $2 \mathrm{kPa}$ & 0.1 & - & $1.1 / 2.4$ & $6 / 0$ & & & 1.55 & 0.2 & 1.23 & & \\
\hline 28 & 180 & 36 & $\sim=\mathrm{Ta}$ & $4 / 2 \mathrm{kPa}$ & 0.1 & - & & $6 / 0$ & 0.1 & 0.013 & 0.93 & 0.21 & 0.88 & 0.20 & \\
\hline 29 & & $23 / 50$ & $\sim=\mathrm{Ta}$ & $2 \mathrm{kPa}$ & 0.1 & - & $1.1 / 2.4$ & $6 / 0$ & & & 1.47 & 0.19 & 1.28 & 0.10 & \\
\hline 30 & 165 & $40 / 40$ & $\sim=\mathrm{Ta}$ & $65 \%$ & 0.1 & - & $1.0 / 2.3 /$ & $8 / 0$ & & & - & 0.15 & - & -0.09 & \\
\hline 31 & 180 & $23 / 50$ & $\sim=\mathrm{Ta}$ & $2 \mathrm{kPa}$ & 0.1 & - & $\frac{2.950 .6}{1.1 / 2.3}$ & $8 / 0$ & & & 1.34 & 0.33 & 1.10 & 0.29 & unpublished from Biomed \\
\hline 32 & 165 & $40 / 30$ & $\sim=\mathrm{Ta}$ & $65 \%$ & 0.1 & - & $\begin{array}{l}1.0 / 2.3 / \\
29 / 3.6\end{array}$ & $8 / 0$ & 0.1 & 0.013 & - & 0.20 & - & -0.12 & database \\
\hline 33 & 166 & $40 / 25$ & $\sim=\mathrm{Ta}$ & $5 / 2 \mathrm{kPa}$ & 0.1 & - & $\begin{array}{l}2.970 .0 \\
1.0 / 2.3 /\end{array}$ & $8 / 0$ & & & - & 0.29 & - & -0.28 & \\
\hline 34 & 160 & $28 / 36$ & $28 / 36$ & $6 \mathrm{kPa}$ & 0.5 & - & $2.4 / 1.4$ & $5 / 0 \times 6$ & \begin{tabular}{|l|l|}
$0.1-0.6$ \\
\end{tabular} & 0.013 & 0.36 & 0.17 & 0.24 & 5 & \\
\hline & $\frac{16}{16}$ & 47 & 36 & & 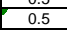 & - & & 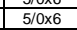 & & & 1. & & 0.24 & & \\
\hline 6 & 160 & 35 & 14 & $0.9 \mathrm{kPa}$ & 0.5 & - & $2.1 / 1.4$ & $5 / 0 \times 6$ & $0.1-0.6$ & & 1.09 & 0. & 1.00 & 0.07 & \\
\hline 37 & 160 & 36 & 57 & $0.9 \mathrm{kPa}$ & 0.5 & - & $2.1 / 1.4$ & $5 / 0 \times 6$ & \begin{tabular}{|l|}
$0.1-0.6$ \\
\end{tabular} & 0.013 & 0.76 & 0.36 & 0.64 & 0.31 & \\
\hline
\end{tabular}

\begin{tabular}{|c|c|c|c|c|c|c|c|c|c|c|c|c|c|c|c|c|}
\hline 38 & 430 & $-3 / 22$ & $-11 / 22$ & $60 / 98 \%$ & $0.2 / 2.6$ & $0 / 128$ & $1.0 / 3.0$ & $1 / 0$ & $\begin{array}{c}0.87 / 1.37 ; \\
1.25 / 1.43\end{array}$ & $0.02 ; 0.04$ & 1.75 & 0.25 & -0.07 & 0.16 & min/max \\
\hline 39 & 407 & $-4 / 21$ & $-11 / 21$ & $60 / 71 \%$ & $0.2 / 10.5$ & $0 / 362$ & $0.8 / 4.7$ & $1 / 0$ & $\begin{array}{c}0.94 / 1.49 ; \\
1.07 / 1.21\end{array}$ & $0.02 ; 0.04$ & 2.78 & 0.23 & 1.46 & -0.14 \\
\hline 40 & 347 & $-3 / 20$ & $-12 / 20$ & $60 / 96 \%$ & $0.2 / 2.4$ & $0 / 55$ & $0.8 / 4.0$ & $1 / 0$ & $\begin{array}{c}0.92 / 1.46 ; \\
1.22 / 1.40\end{array}$ & $0.02 ; 0.04$ & 2.05 & 0.18 & 1.20 & 0.06 & $\begin{array}{c}\text { minpublished from K. Blazejczyk, } \\
\text { PAN, Warsaw, Poland }\end{array}$ \\
\hline 41 & 460 & $-7 / 20$ & $-11 / 22$ & $42 / 60 \%$ & $0.2 / 2.8$ & $0 / 411$ & $1.0 / 4.7$ & $1 / 0$ & $\begin{array}{c}0.92 / 1.45 ; \\
1.24 / 1.41\end{array}$ & $0.02 ; 0.04$ & 1.44 & 0.20 & 0.34 & -0.14 & \\
\hline
\end{tabular}
\begin{tabular}{|l|l|l|l|l|l|l|l|l|l|l|l|l|l|l|l|}
\hline 42 & & & & & & & & & & & \\
\hline
\end{tabular}

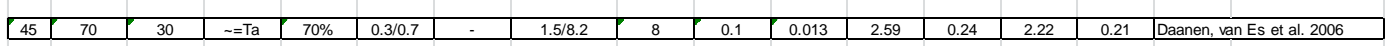

\begin{tabular}{|c|c|c|c|c|c|c|c|c|c|c|c|c|c|c|c|}
\hline 46 & \multirow{10}{*}{120} & & & & \multirow{10}{*}{0.3} & \multirow{10}{*}{-} & $\sim 1.3 / \sim 4.8$ & $1 / 1$ & \multirow{4}{*}{0.23} & \multirow{4}{*}{0.01} & 0.83 & 0.64 & 0.32 & 0.62 & \multirow{14}{*}{$\begin{array}{l}\text { unpublished from E.den Hartog, } \\
\text { TNO Defence, Security and } \\
\text { Safety, Netherlands }\end{array}$} \\
\hline 47 & & 30 & $\sim=1 \mathrm{a}$ & $20 \%$ & & & $\sim 1.3 / \sim 1.8$ & $1 / 1$ & & & 2.02 & 0.62 & -0.76 & 0.47 & \\
\hline 48 & & & & & & & $\sim 1.3 / \sim 4.8$ & $1 / 1$ & & & 1.13 & 0.69 & 0.51 & 0.65 & \\
\hline 49 & & 30 & $\sim=\mathrm{Ta}$ & $80 \%$ & & & $\sim 1.3 / \sim 1.8$ & $1 / 1$ & & & 1.24 & 0.86 & 0.34 & 0.79 & \\
\hline 50 & & 20 & $\sim=\mathrm{Ta}$ & $50 \%$ & & & $\sim 1.3 / \sim 4.8$ & $1 / 1$ & \multirow{6}{*}{0.73} & \multirow{6}{*}{0.02} & 0.93 & 0.64 & 0.35 & 0.63 & \\
\hline 51 & & & & & & & $\sim 1.3 / \sim 1.8$ & $1 / 1$ & & & 2.21 & 0.72 & -1.15 & -0.31 & \\
\hline 52 & & 5 & $\sim=\mathrm{T}$ & $50 \%$ & & & $\begin{array}{c}\sim 1.3 / \sim 4.8 \\
\end{array}$ & $2 / 0$ & & & 1.08 & 0.30 & -0.98 & 0.28 & \\
\hline 53 & & 5 & & $50 \%$ & & & $\sim 1.3 / \sim 1.8$ & $1 / 1$ & & & 2.01 & 0.32 & -1.90 & 0.19 & \\
\hline$\frac{54}{55}$ & & & & & & & $\sim 1.3 / \sim 4.8$ & $2 / 0$ & & & 3.50 & 0.42 & -3.44 & 0.22 & \\
\hline 55 & & -5 & $\sim$ Ta & $50 \%$ & & & $\sim 1.3 / \sim 1.8$ & $2 / 0$ & & & 6.59 & 0.44 & -6.56 & 0.29 & \\
\hline 56 & 75 & 10 & $\sim=\mathrm{Ta}$ & $60 \%$ & $0.3 / 1.0$ & - & $3.8 / 5.2 / 1.2$ & $12 / 0 \times 3$ & 1.0 & 0.02 & 0.58 & 0.28 & -0.20 & -0.07 & \\
\hline 57 & 56 & \multirow{3}{*}{30} & \multirow{3}{*}{$\sim=\mathrm{Ta}$} & \multirow{3}{*}{$80 \%$} & \multirow{3}{*}{0.3} & \multirow{3}{*}{600} & $1.3 / 7.4 / 9.4$ & $0 / 1$ & \multirow{3}{*}{0.12} & \multirow{3}{*}{0.01} & 0.55 & 0.44 & 0.04 & -0.19 & \\
\hline 58 & 56 & & & & & & $1.3 / 7.2 / 9.2$ & $0 / 1$ & & & 0.60 & 0.46 & 0.13 & 0.36 & \\
\hline 59 & 90 & & & & & & $1.3 / 9.1 / 12$ & $1 / 0$ & & & 0.88 & 0.38 & -0.03 & 0.31 & \\
\hline
\end{tabular}



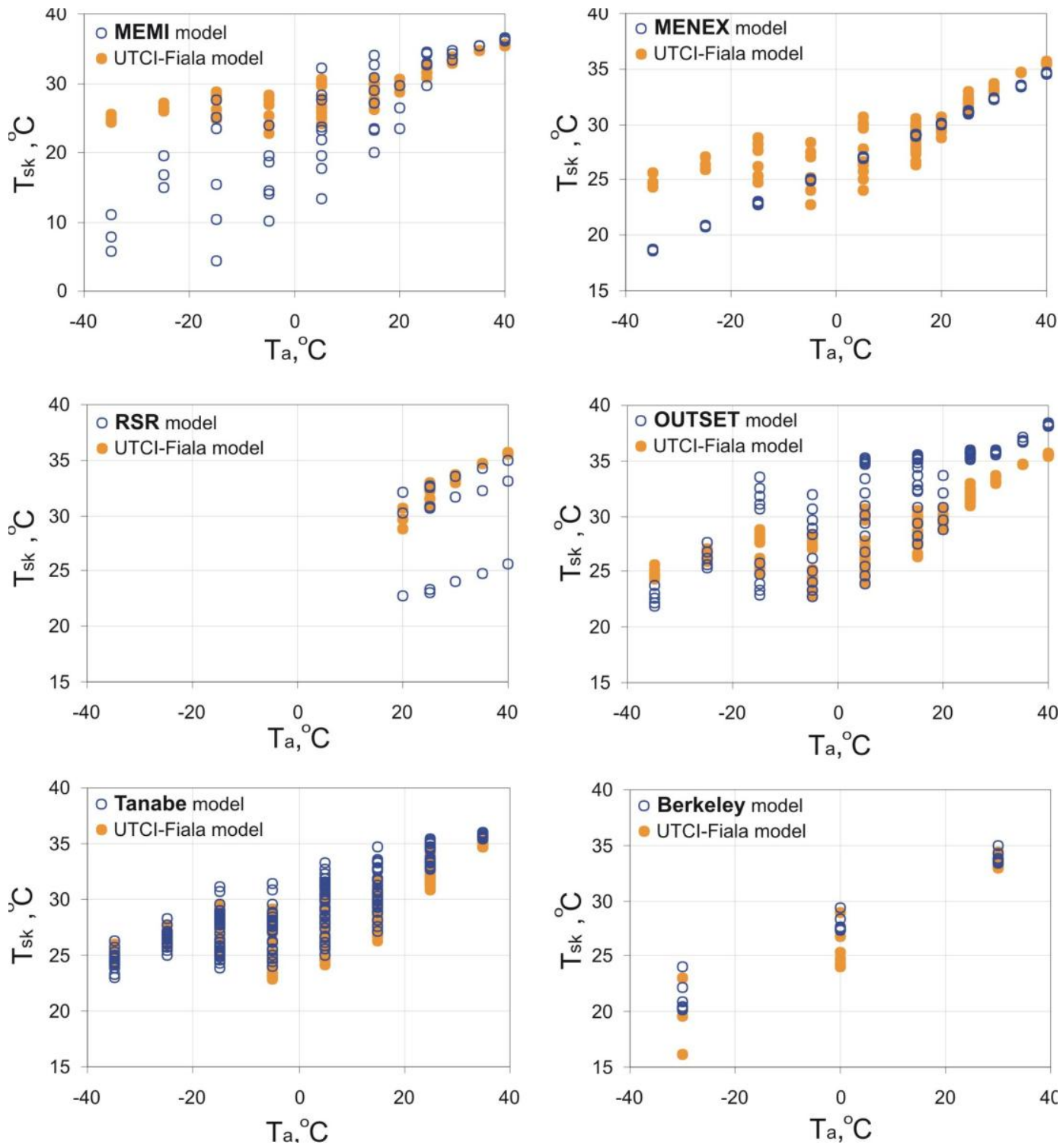

Fig. 1 Comparison of mean skin temperatures $\left(T_{\text {sk }}\right)$ predicted using different models for a wide range of environmental temperature $\left(\mathrm{T}_{\mathrm{a}}\right)$. For model abbreviations see Table 1 

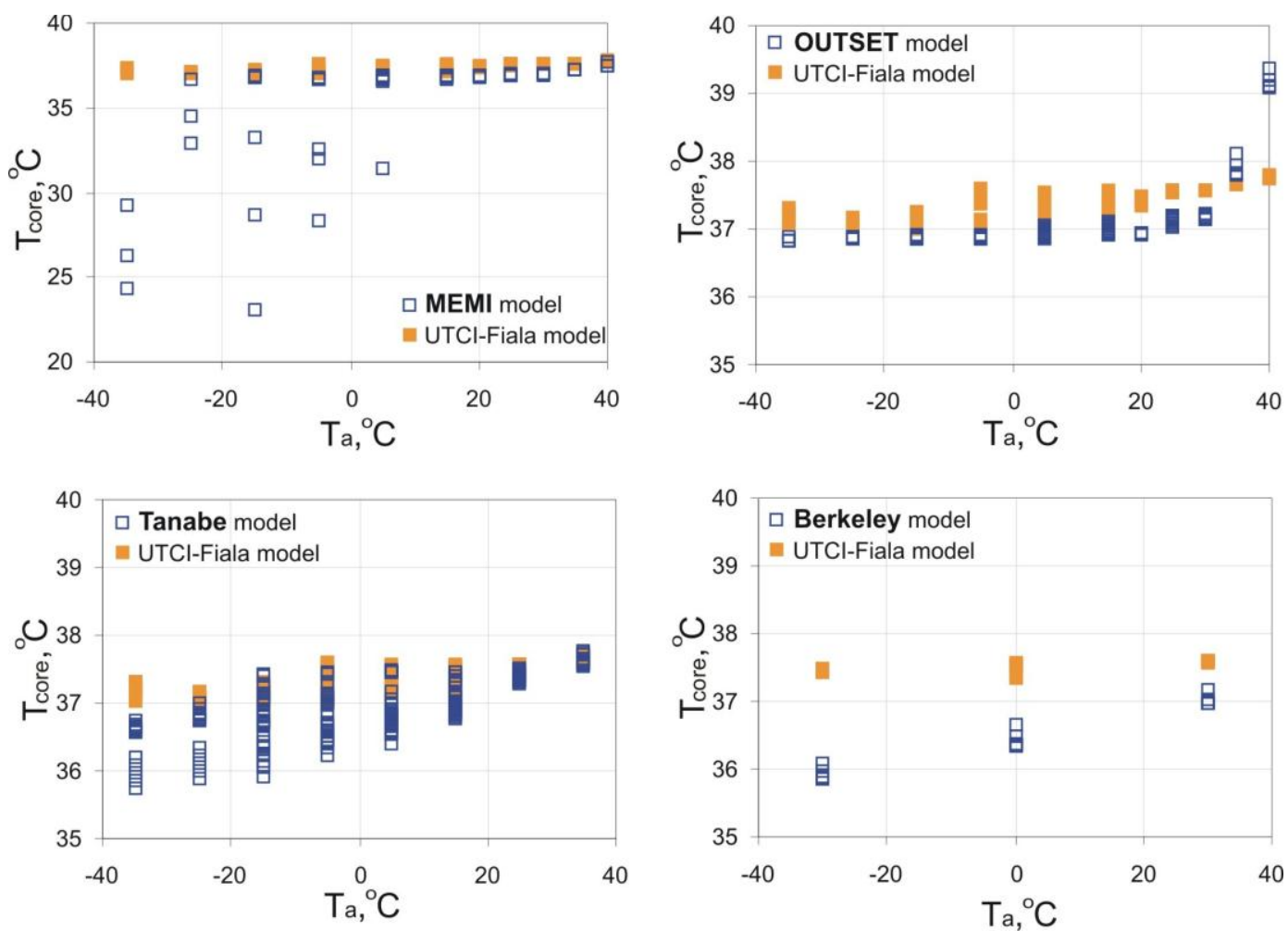

Fig. 2 Comparison of body core temperatures ( $\mathrm{T}_{\text {core }}$ ) predicted using different models (which provided this parameter) for a wide range of environmental temperature $\left(T_{a}\right)$. For model abbreviations see Table 1 


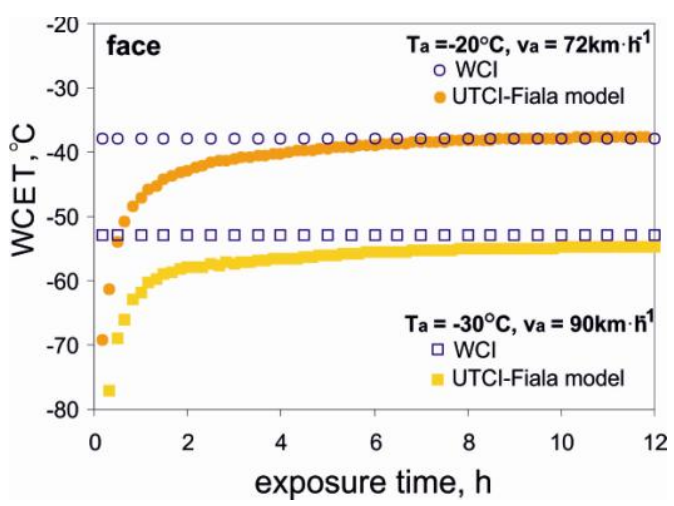

Fig. 3 Wind Chill Equivalent Temperatures (WCET) predicted using the new WCI model and the dynamic UTCI-Fiala model for two different combinations of air temperature and wind speed 


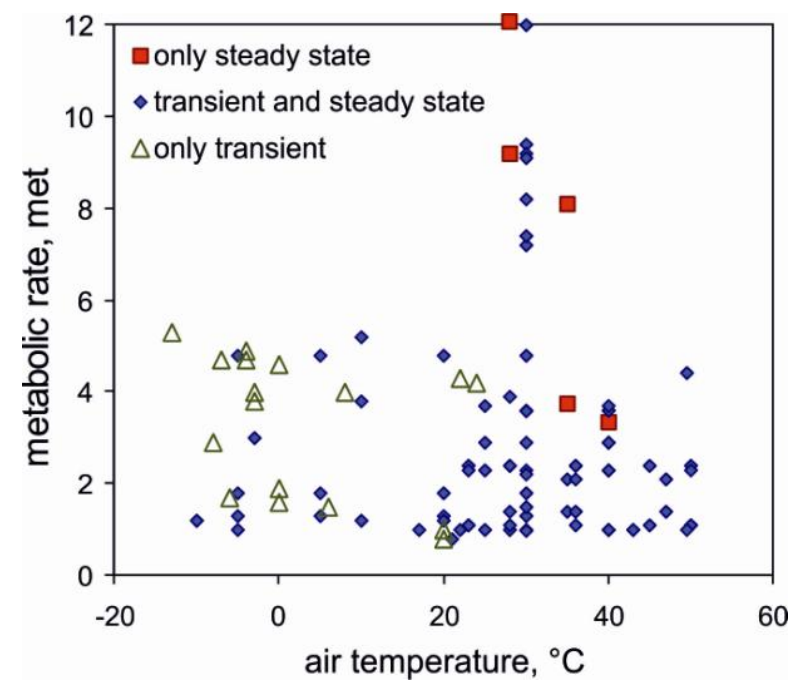

Fig. 4 Distribution of the exposures in the database in relation to the ambient temperature, the metabolic rate, and the stability of conditions during the exposure 

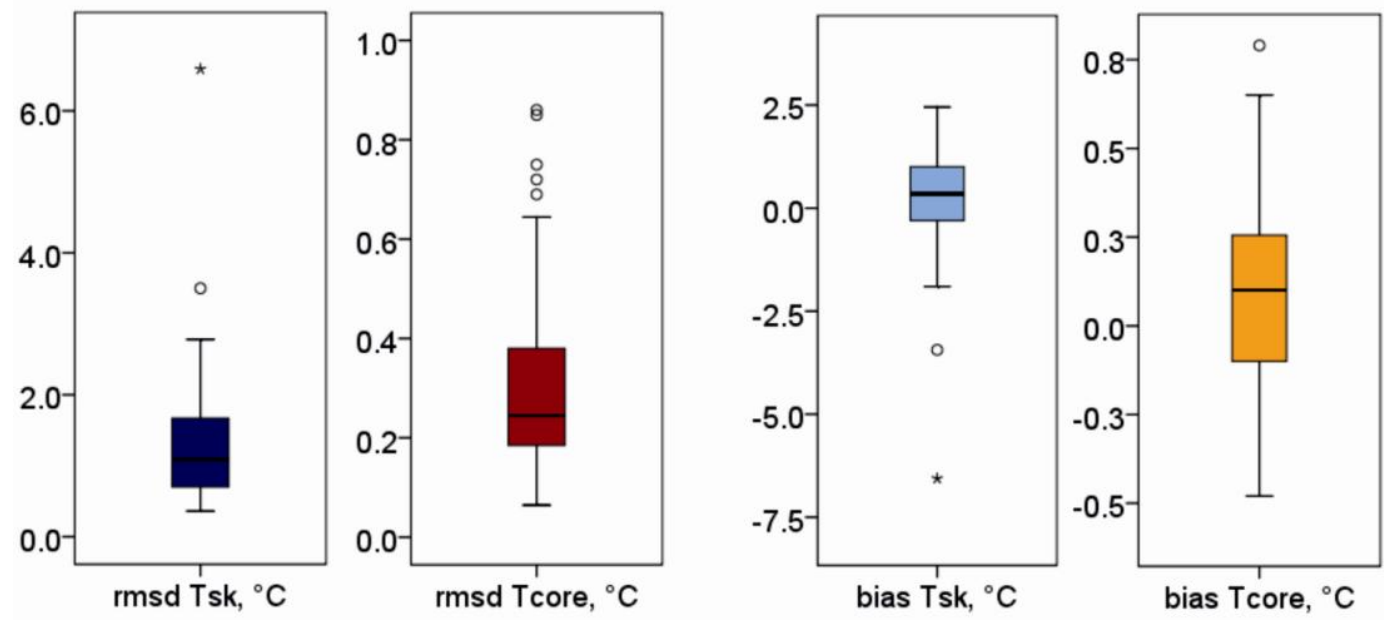

Fig. 5 Box plots of rmsd for the mean skin and core temperatures as summary statistics of the COST 730 validation study 

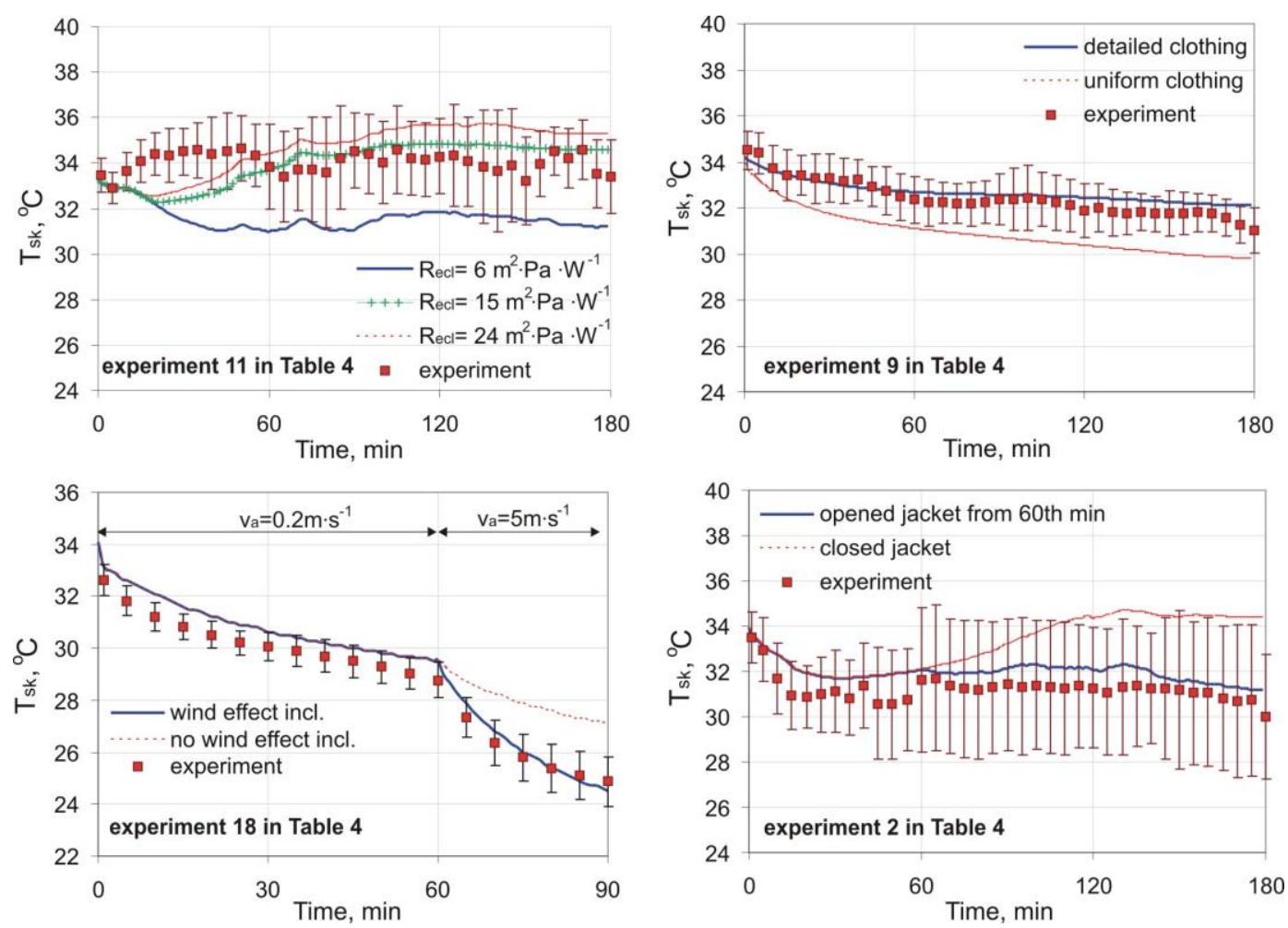

Fig. 6 Mean skin temperatures measured and predicted for four examples of experiments where detailed analysis of the clothing was necessary, such as determination of the correct evaporative resistance of the ensemble (exp. 11 in Table 4), modelling of the distribution of the thermal insulation (exp. 9 in Table 4), considering the wind and walking correction coefficient for thermal and evaporative resistances $\left(\mathrm{R}_{\mathrm{ecl}}\right)$ (exp. 18 in Table 4), and reconstruction of the exact course of the experiment (exp. 2 in Table 4) 

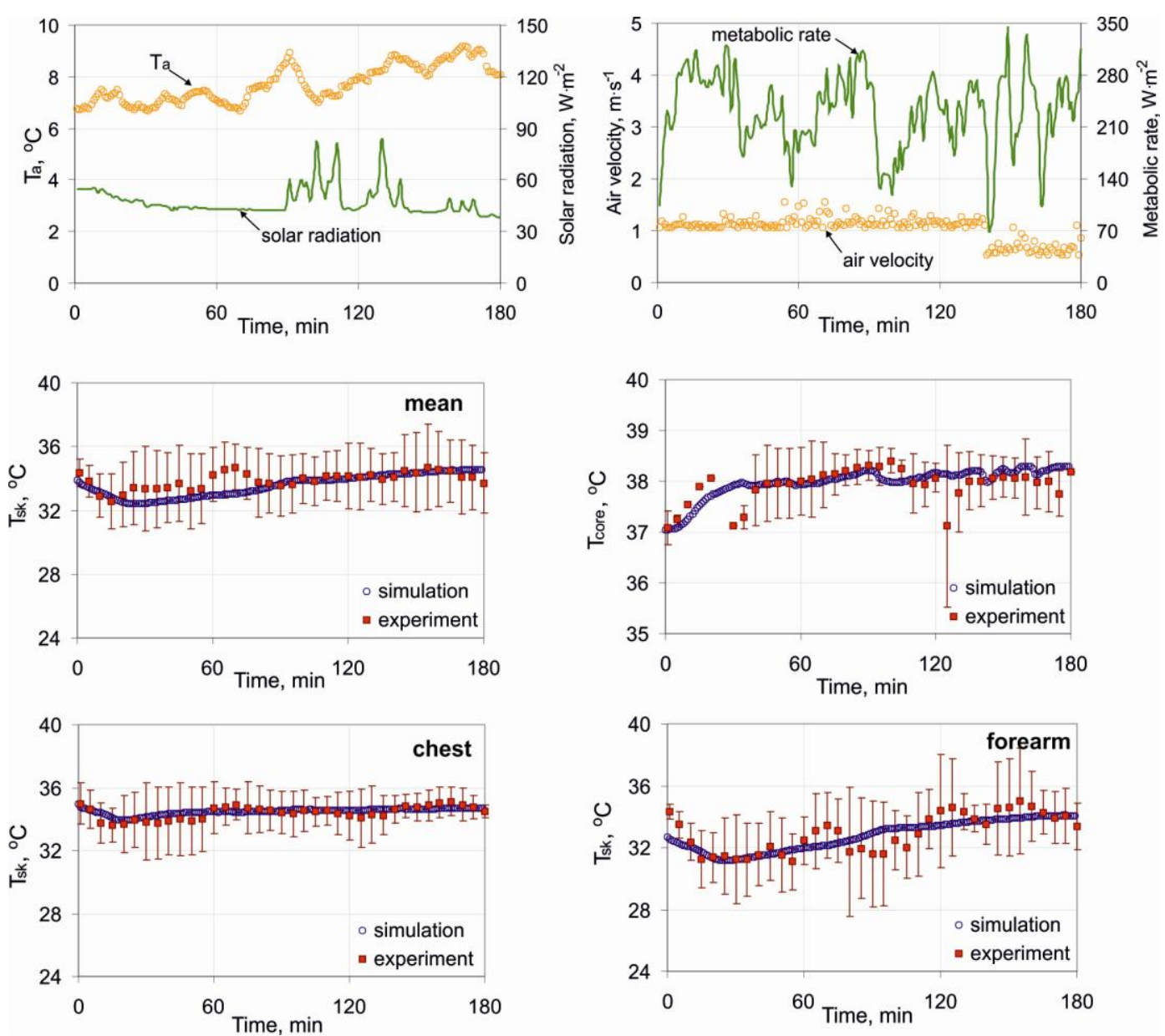

Fig. 7 Experimental conditions, mean and local temperatures $\left(\mathrm{T}_{\text {sk }}\right)$ and core temperatures $\left(\mathrm{T}_{\text {core }}\right)$ measured in an experiment conducted outdoors in winter conditions with subjects wearing winter combat suit and long underwear (exp. 1 in Table 4) 

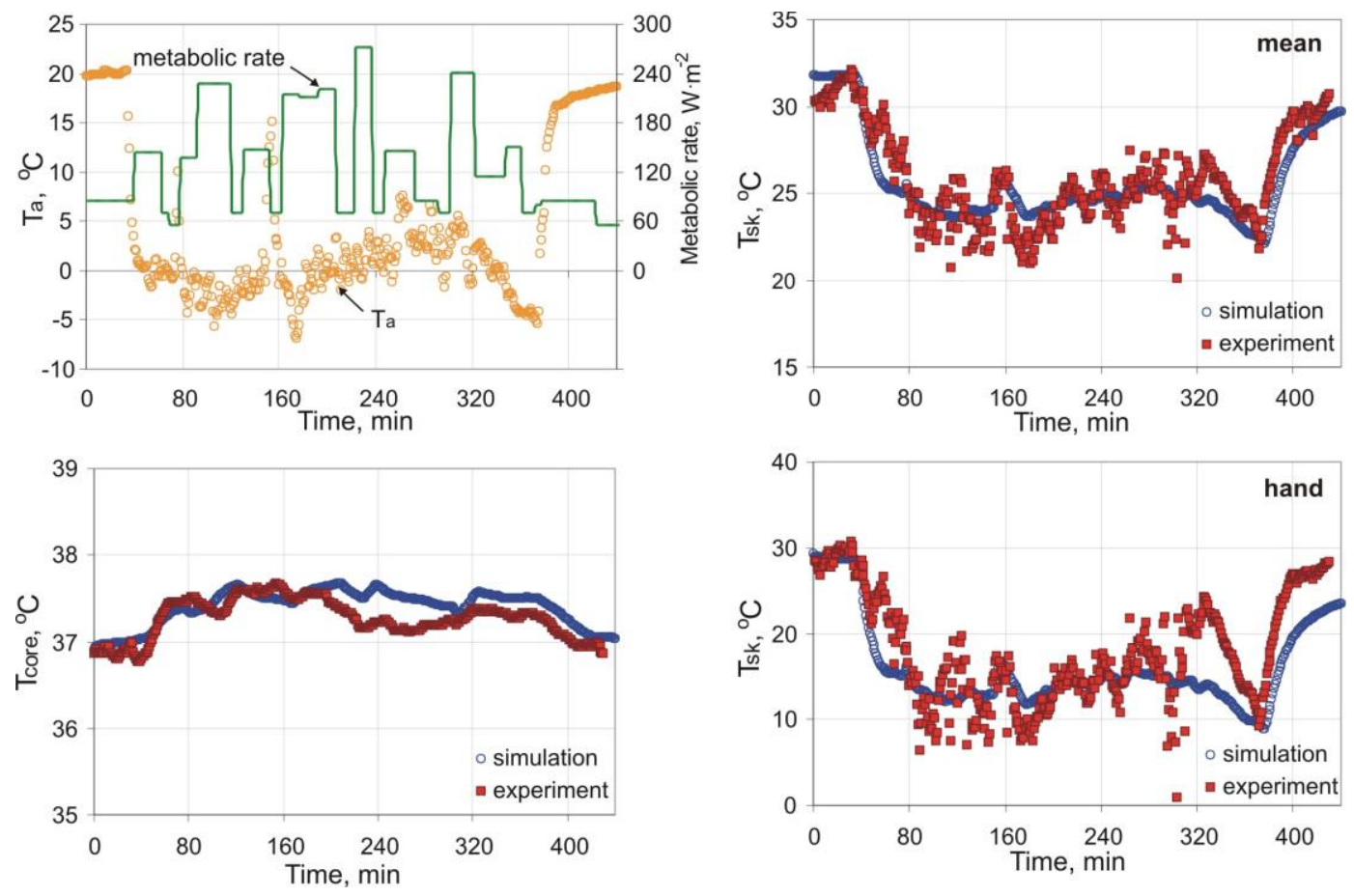

Fig. 8 Experimental conditions $\left(T_{a}\right)$, mean and hand temperatures $\left(T_{s k}\right)$ and core temperatures $\left(\mathrm{T}_{\text {core }}\right.$ ) measured in the experiment conducted indoors (at the beginning and the end) and outdoors in winter conditions with a subject wearing casual clothing (adjusted for outdoors) and long underwear (exp. 41 in Table 4) 

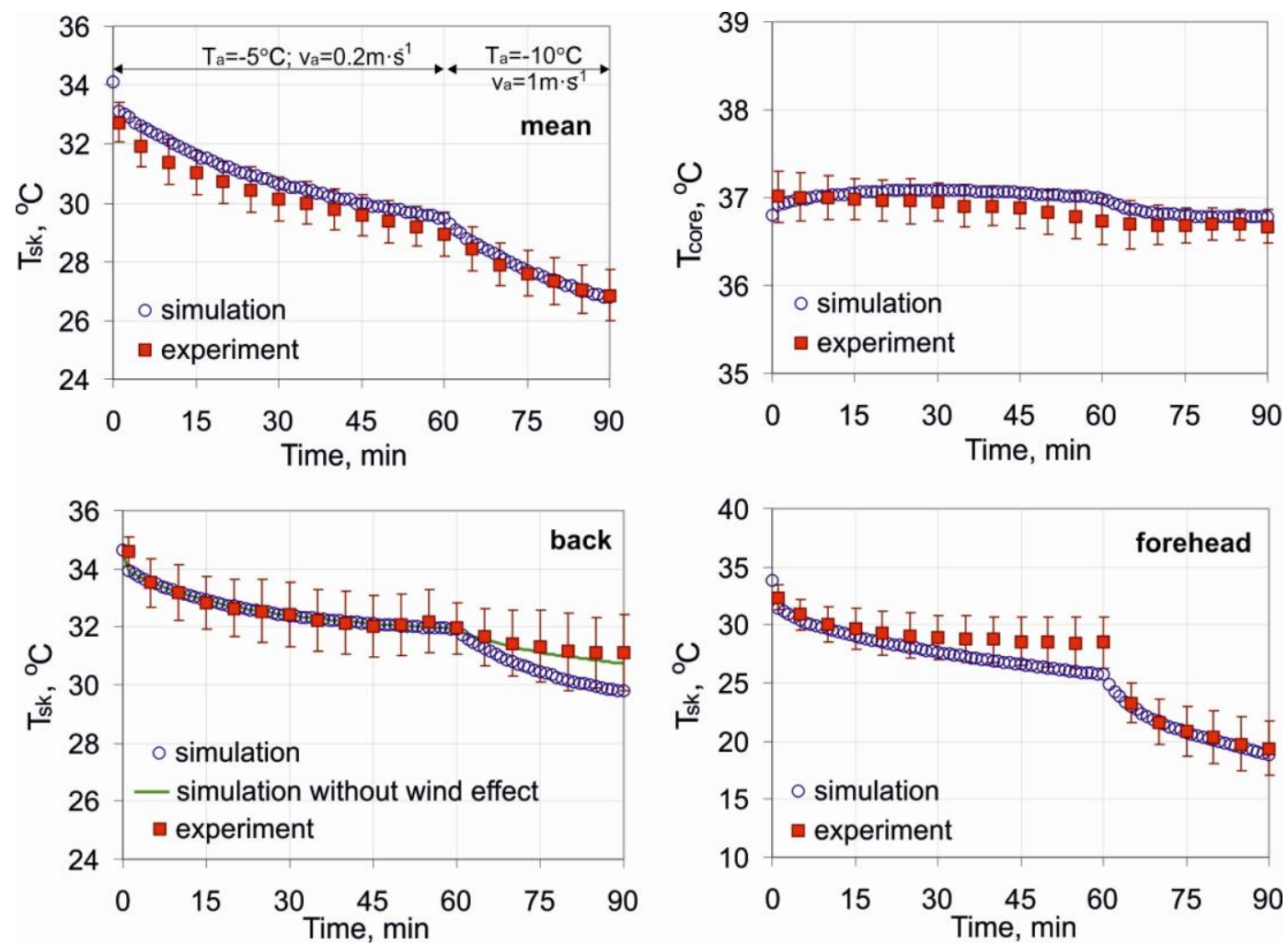

Fig. 9 Measured and predicted mean and local skin temperatures $\left(T_{\text {sk }}\right)$, and rectal temperature $\left(\mathrm{T}_{\text {core }}\right)$ for subjects exposed to cold wind (exp. 17 in Table 4) 


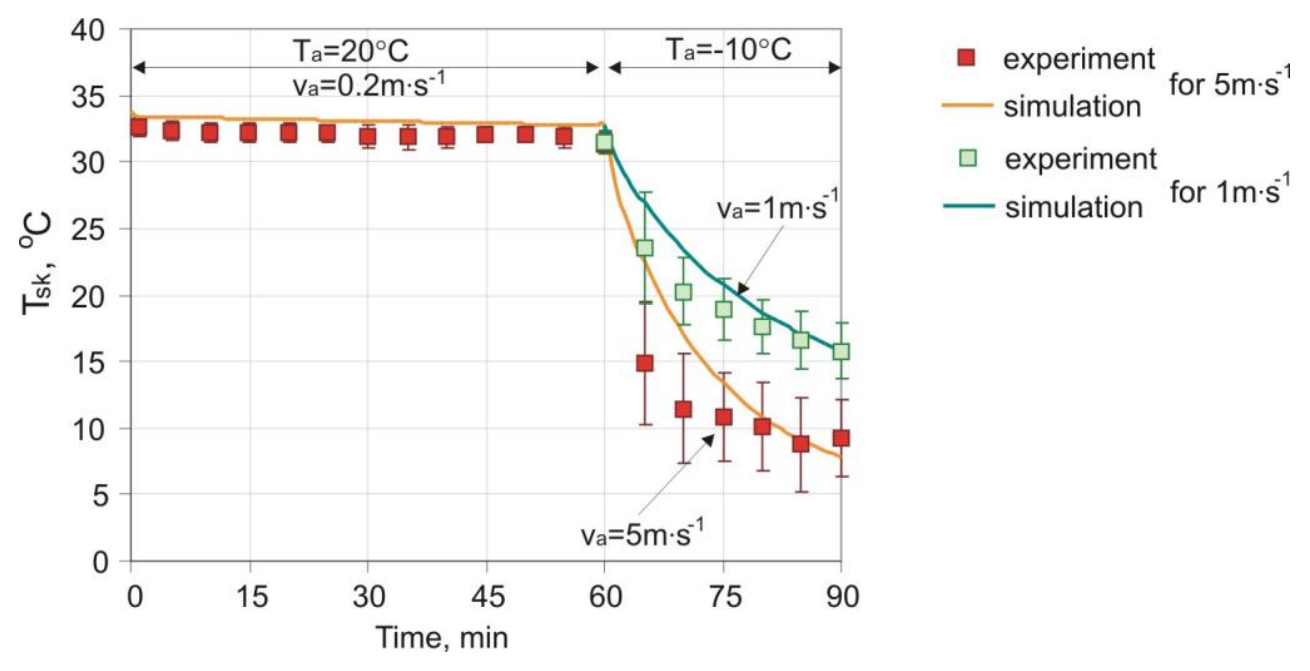

Fig. 10 Measured and predicted cheek skin temperatures $\left(T_{\text {sk }}\right)$ during a sudden decrease in air temperature and increase in the air velocity $\left(\mathrm{v}_{\mathrm{a}}\right)$ (exp. 14 and 15 in Table 4) 

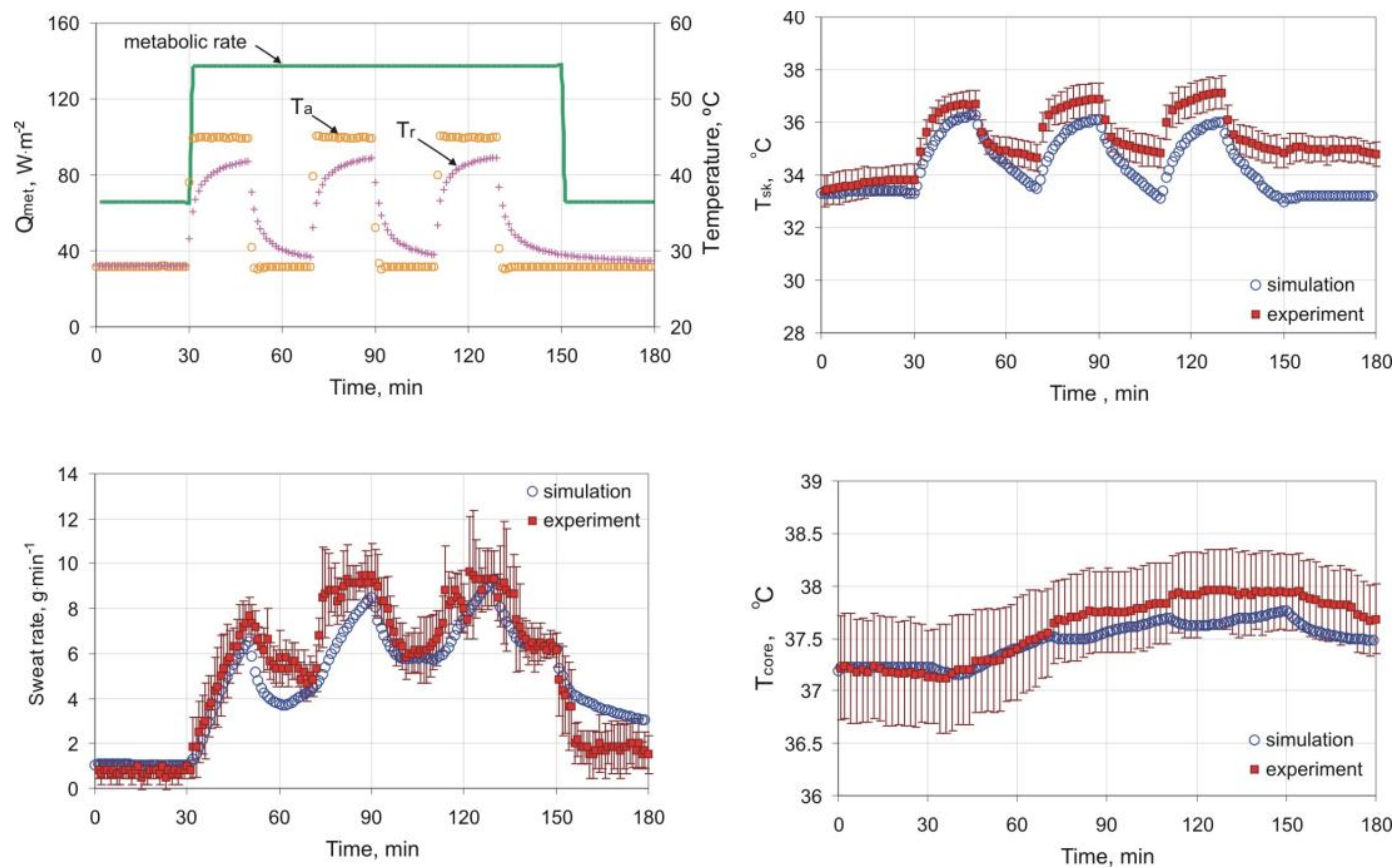

Fig. 11 Measured and predicted mean skin $\left(T_{\text {sk }}\right)$ and core temperatures $\left(T_{\text {core }}\right)$, and sweat rate for subjects exposed to varying air $\left(\mathrm{T}_{\mathrm{a}}\right)$ and radiant $\left(\mathrm{T}_{\mathrm{r}}\right)$ temperatures while working at different metabolic rates $\left(\mathrm{Q}_{\mathrm{met}}\right)$ (exp. 26 in Table 4) 

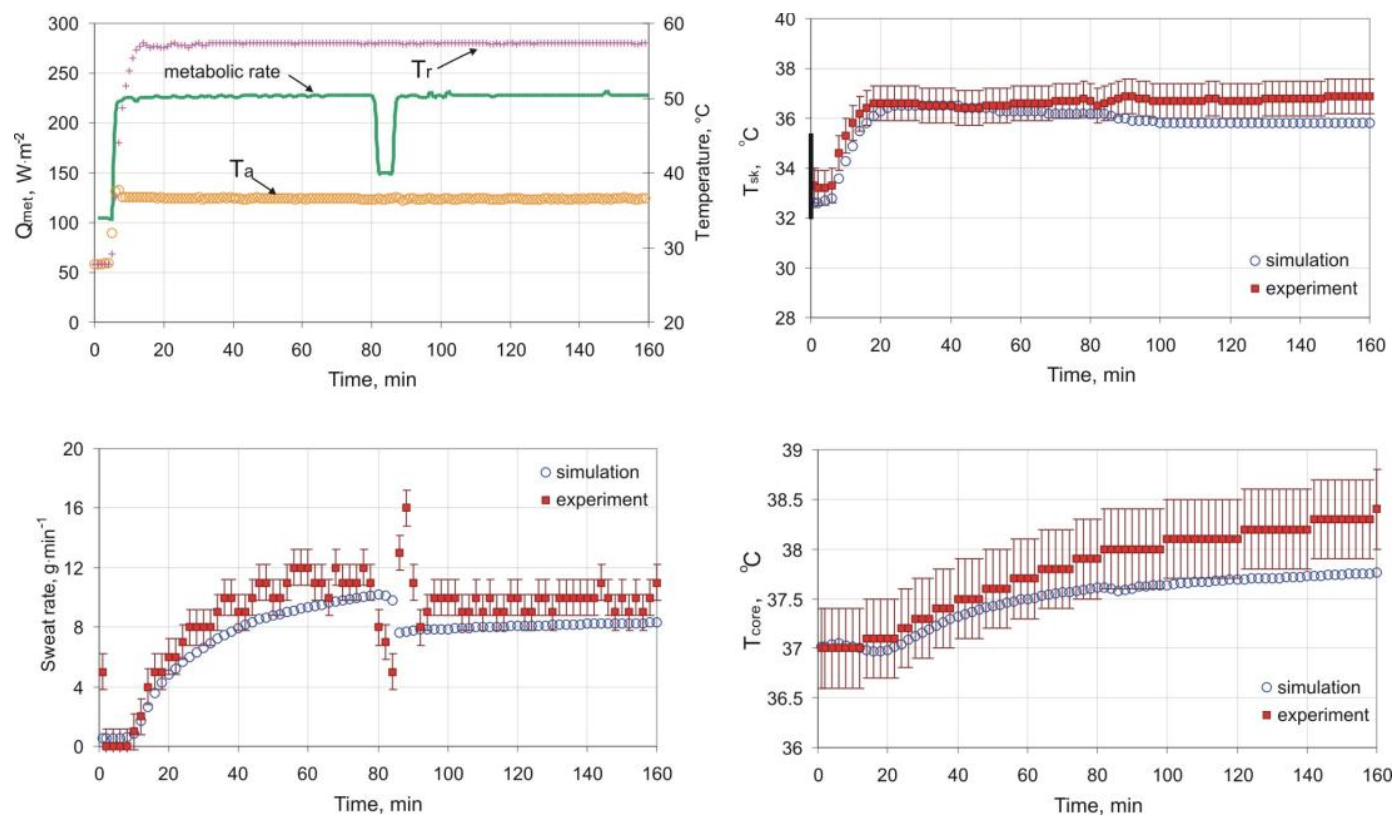

Fig. 12 Measured and predicted mean skin $\left(\mathrm{T}_{\mathrm{sk}}\right)$ and core temperatures $\left(\mathrm{T}_{\mathrm{core}}\right)$, and sweat rate for subjects exposed to environmental conditions with a large difference between air $\left(\mathrm{T}_{\mathrm{a}}\right)$ and radiant $\left(\mathrm{T}_{\mathrm{r}}\right)$ temperatures (exp. 37 in Table 4) 

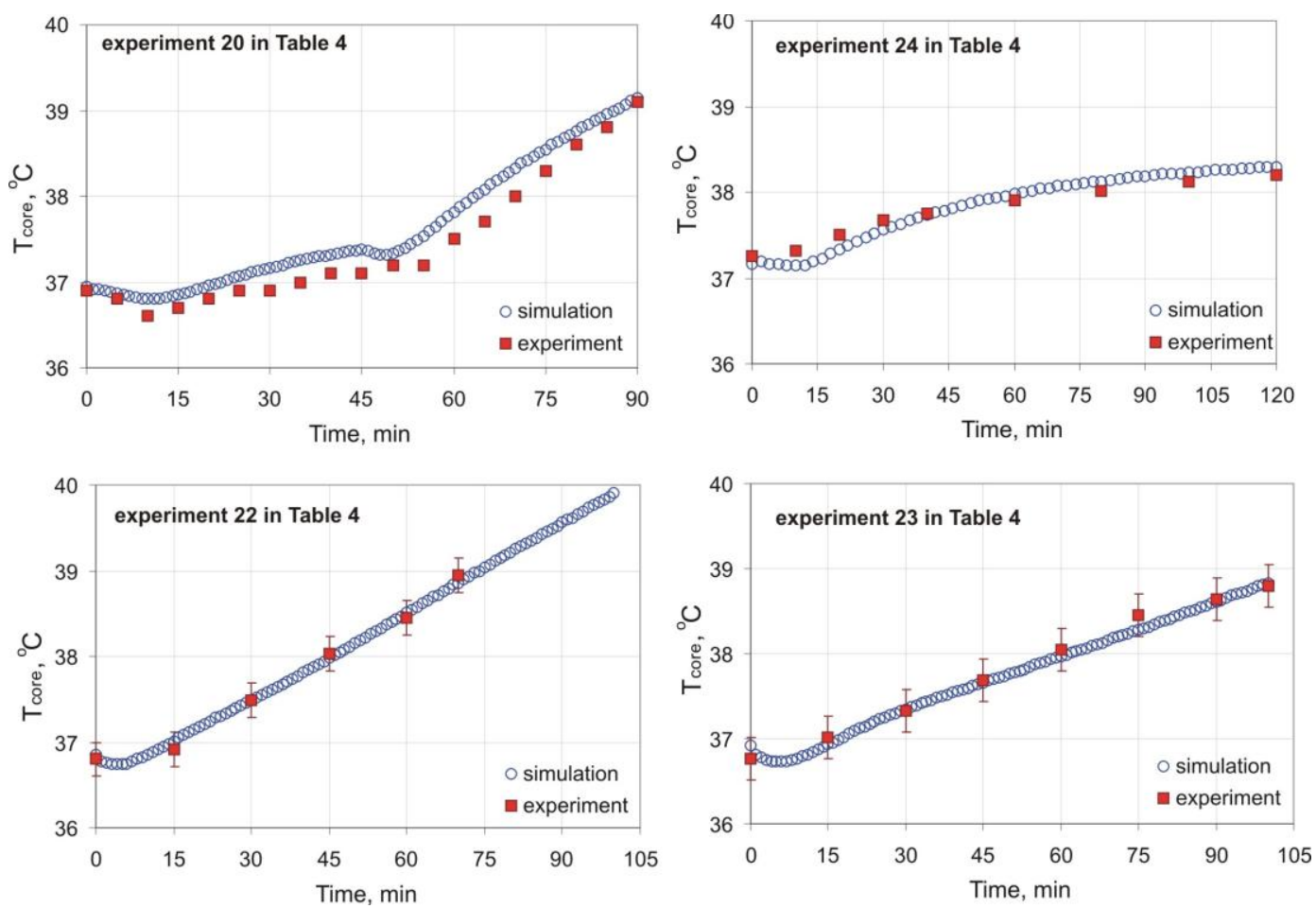

Fig. 13 Body core temperatures ( $T_{\text {core }}$ ) of semi-nude subjects (exp. 20 and 24 in Table 4) and subjects wearing impermeable protective suits (exp. 22 and 23 in Table 4) under hot environmental conditions 

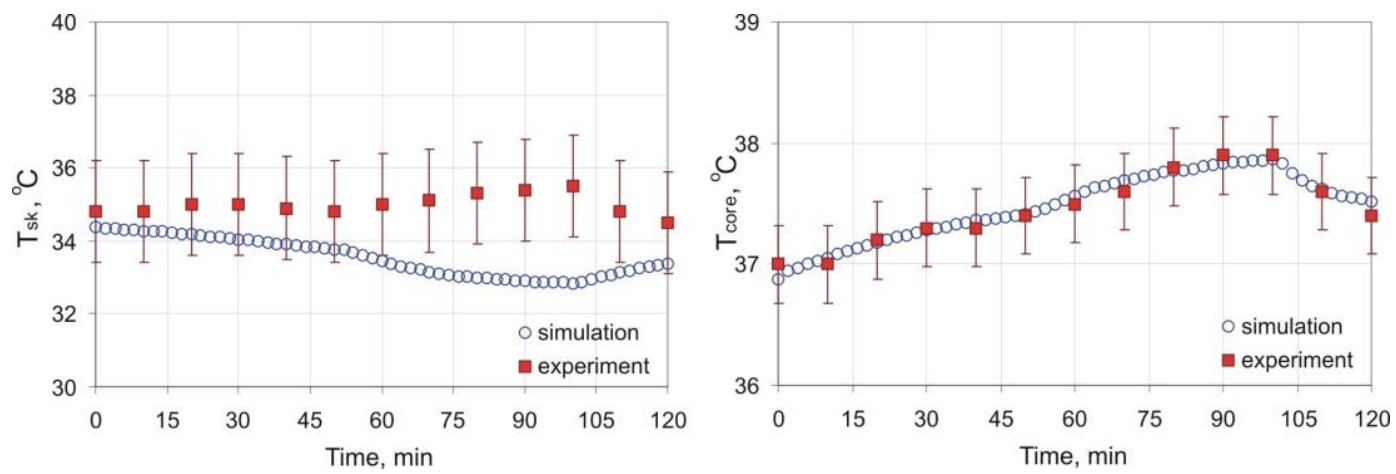

Fig. 14 Mean skin $\left(\mathrm{T}_{\text {sk }}\right)$ and body core temperatures $\left(\mathrm{T}_{\text {core }}\right)$ of semi-nude subjects exercising in hot environmental conditions (exp. 19 in Table 4) 

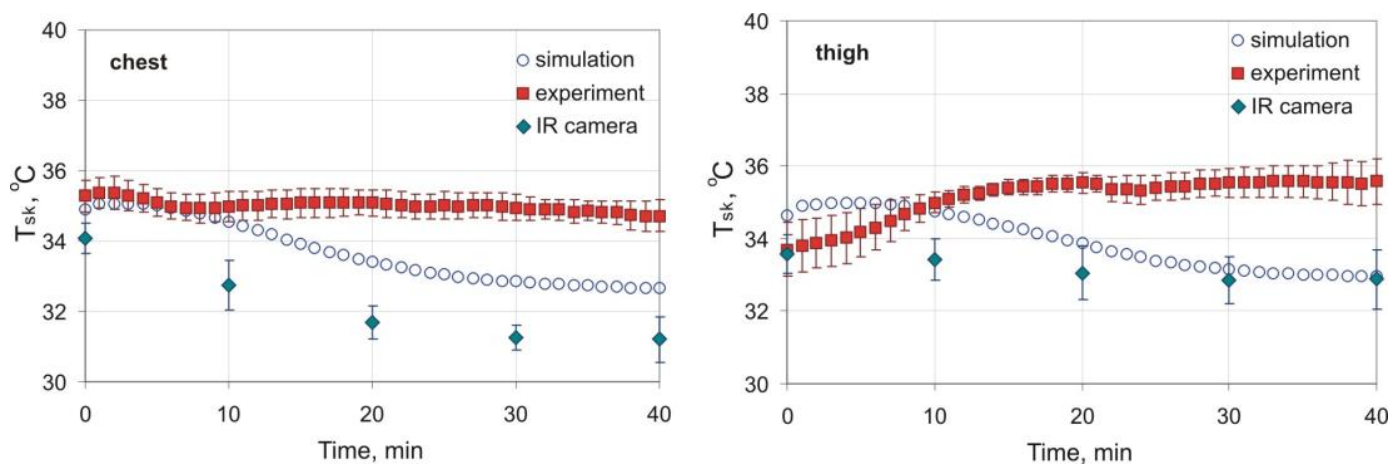

Fig. 15 Chest and thigh skin temperatures $\left(T_{\text {sk }}\right)$ measured in human subjects using taped-over thermistors and infrared camera, and these simulated using the UTCI-Fiala model (exposure 44 in Table 4) 

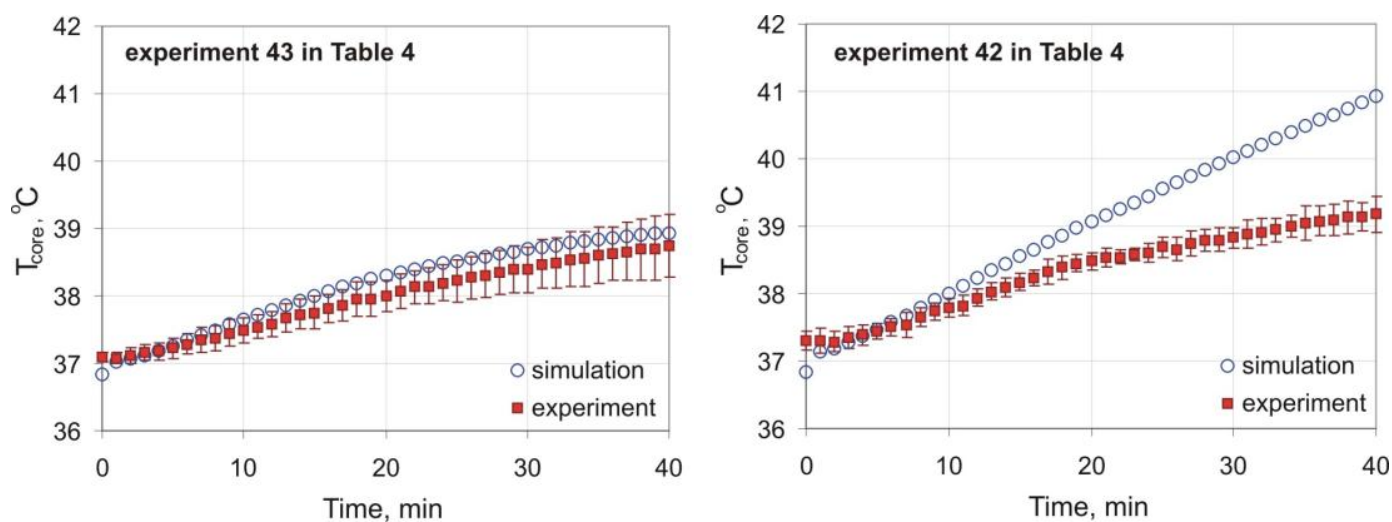

Fig. 16 Body core temperature (rectal) $\left(\mathrm{T}_{\text {core }}\right)$ predicted and measured in untrained subjects (exp. 43 in Table 4) and in professional sportsmen (exp. 42 in Table 4) exercising at 90\% of their individual anaerobic threshold corresponding to metabolic rates of 9.2 met and 12.0 met, respectively 


\section{Electronic Supplemental Materials}

Table 5 General description and root mean square deviations (rmsd) and mean deviations (bias) of all experiments of the COST 730 database for the validation study. $\mathrm{R}_{\mathrm{cl}}$ and $\mathrm{R}_{\mathrm{ecl}}$ are clothing intrinsic thermal and evaporative resistances and $R_{t}$ is clothing total evaporative resistance.

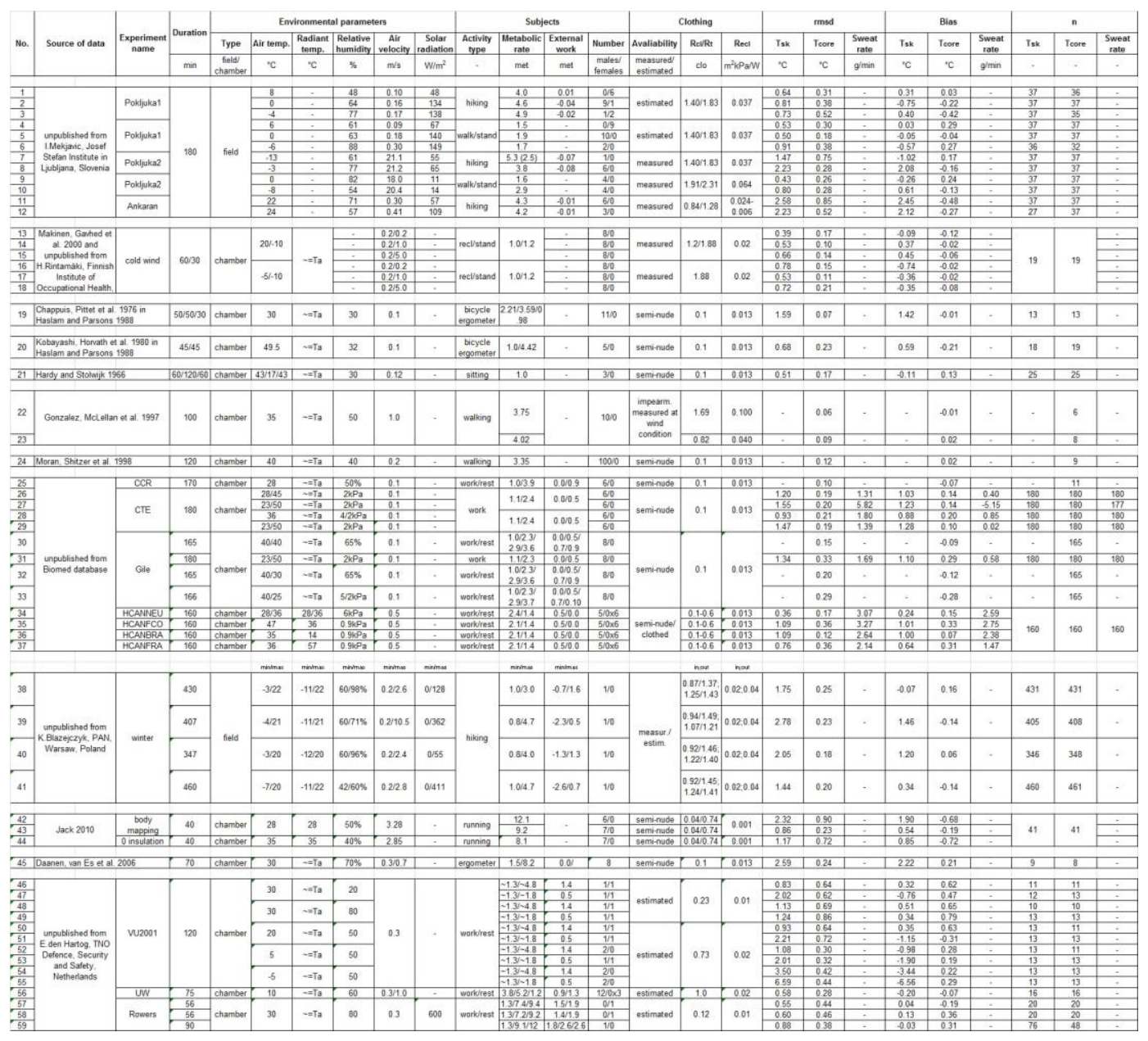



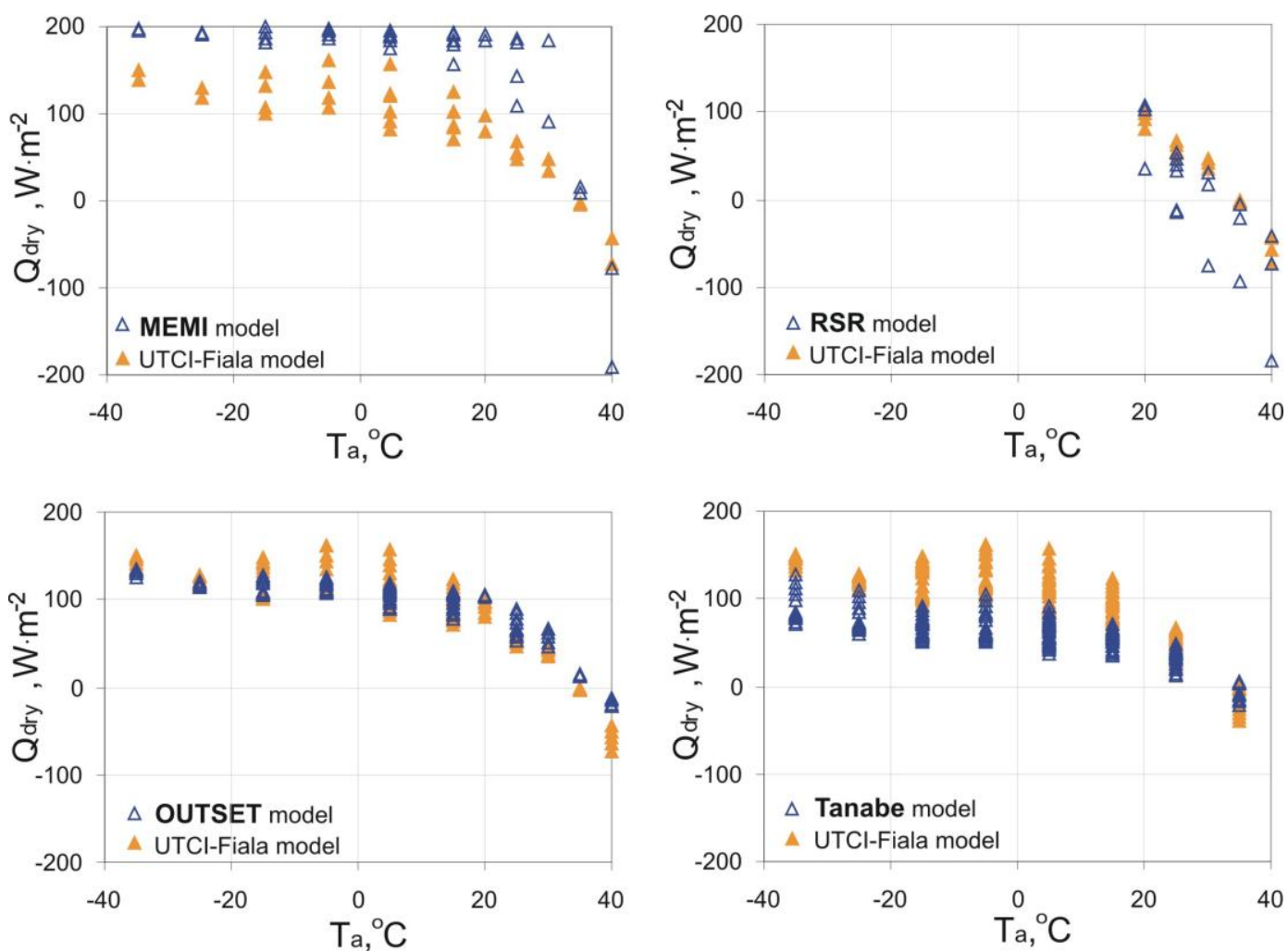

Fig. 17 Comparison of dry heat loss (Qdry) predicted using different models for a wide range of environmental temperature (Ta). For model abbreviations see Table 1 

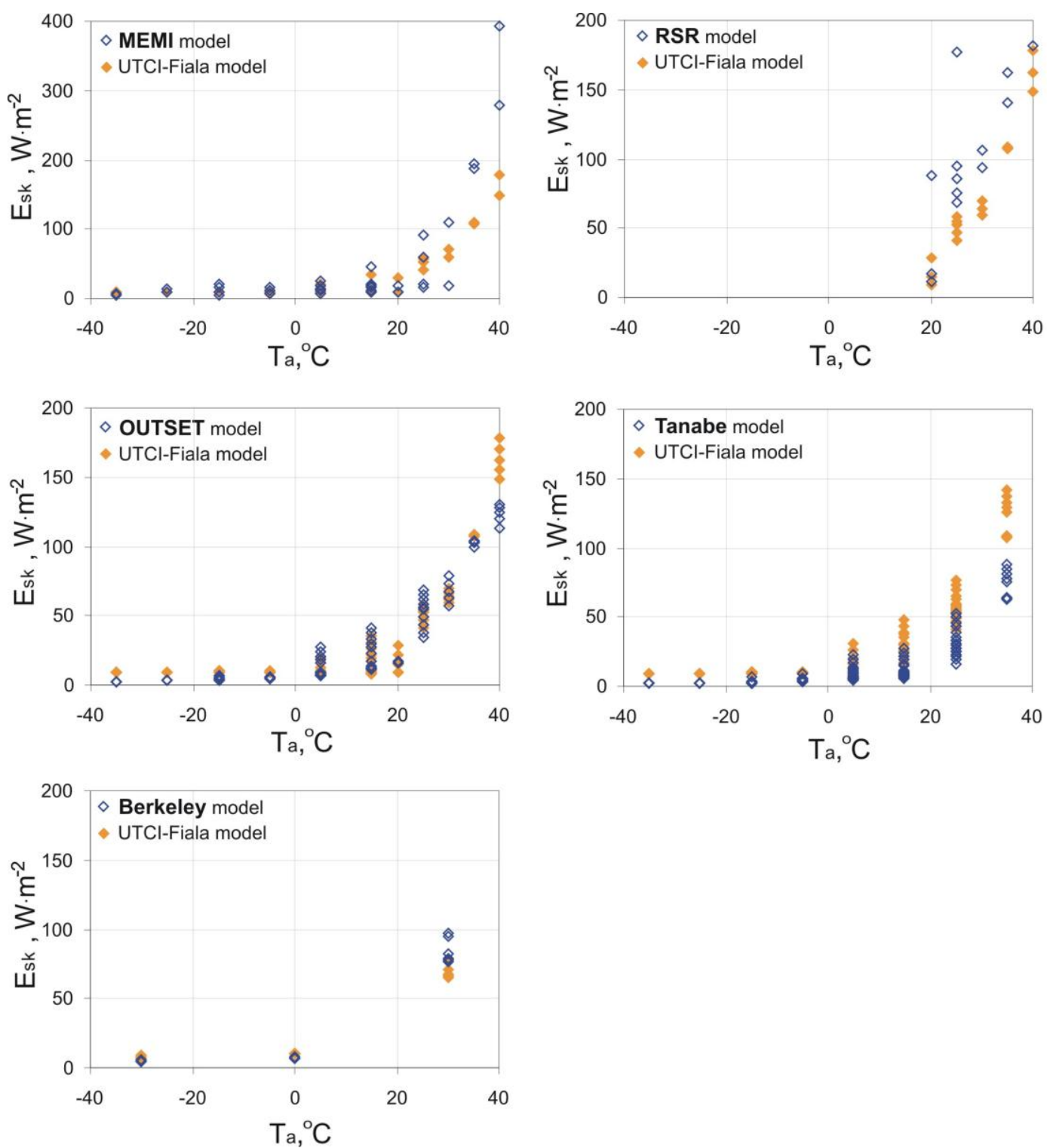

Fig. 18 Comparison of sweat evaporation at the skin $\left(\mathrm{E}_{\mathrm{sk}}\right)$ responses predicted using different models for a wide range of environmental temperature $\left(\mathrm{T}_{\mathrm{a}}\right)$. For model abbreviations see Table 1 

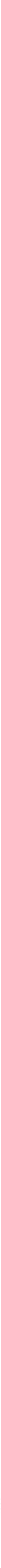

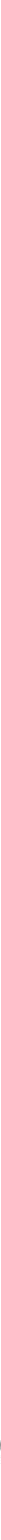


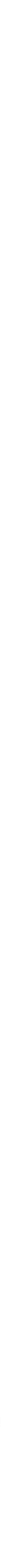



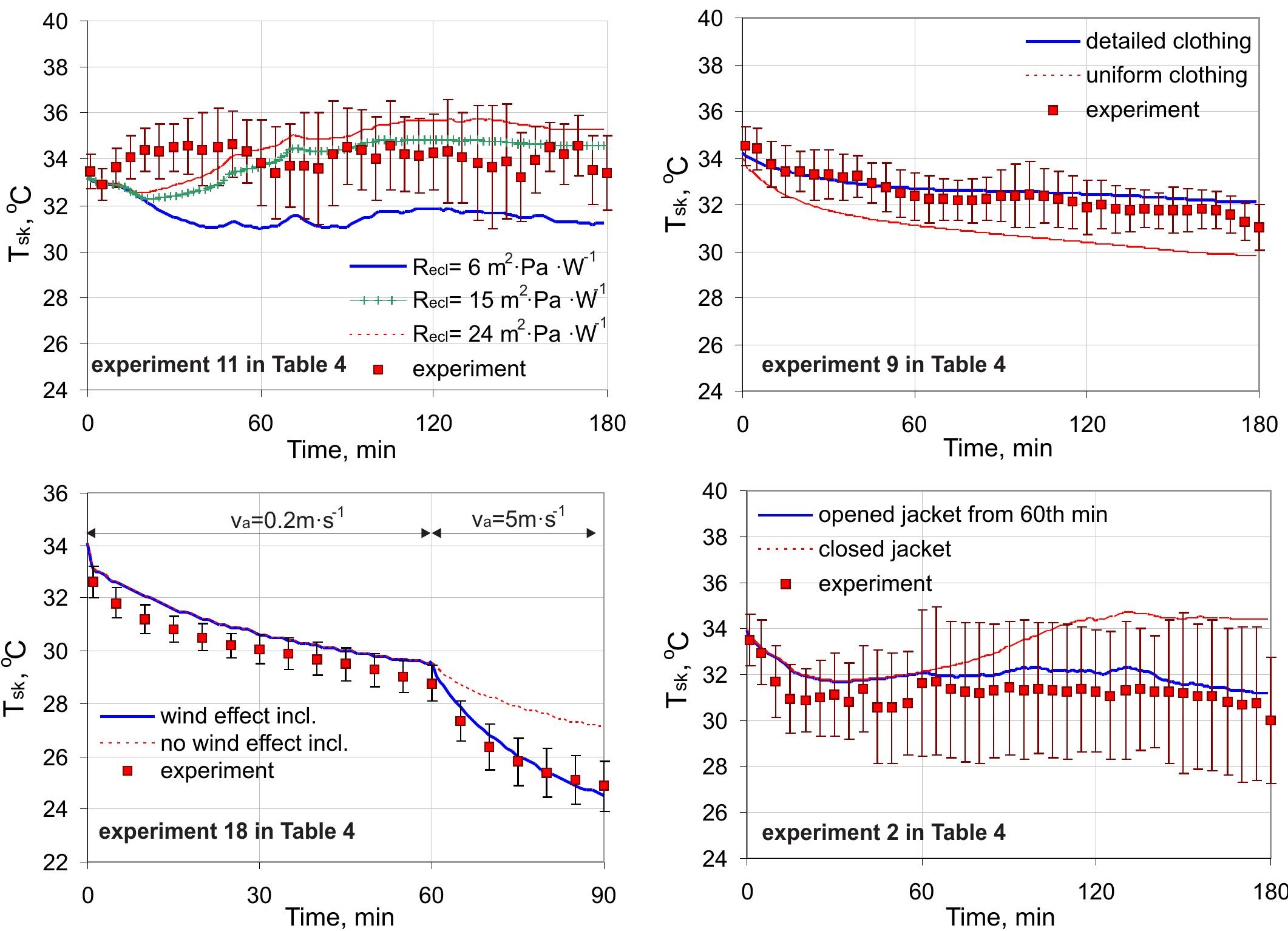

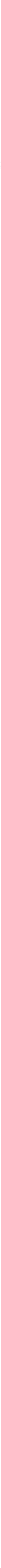

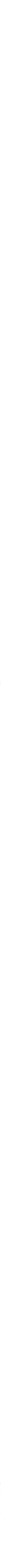


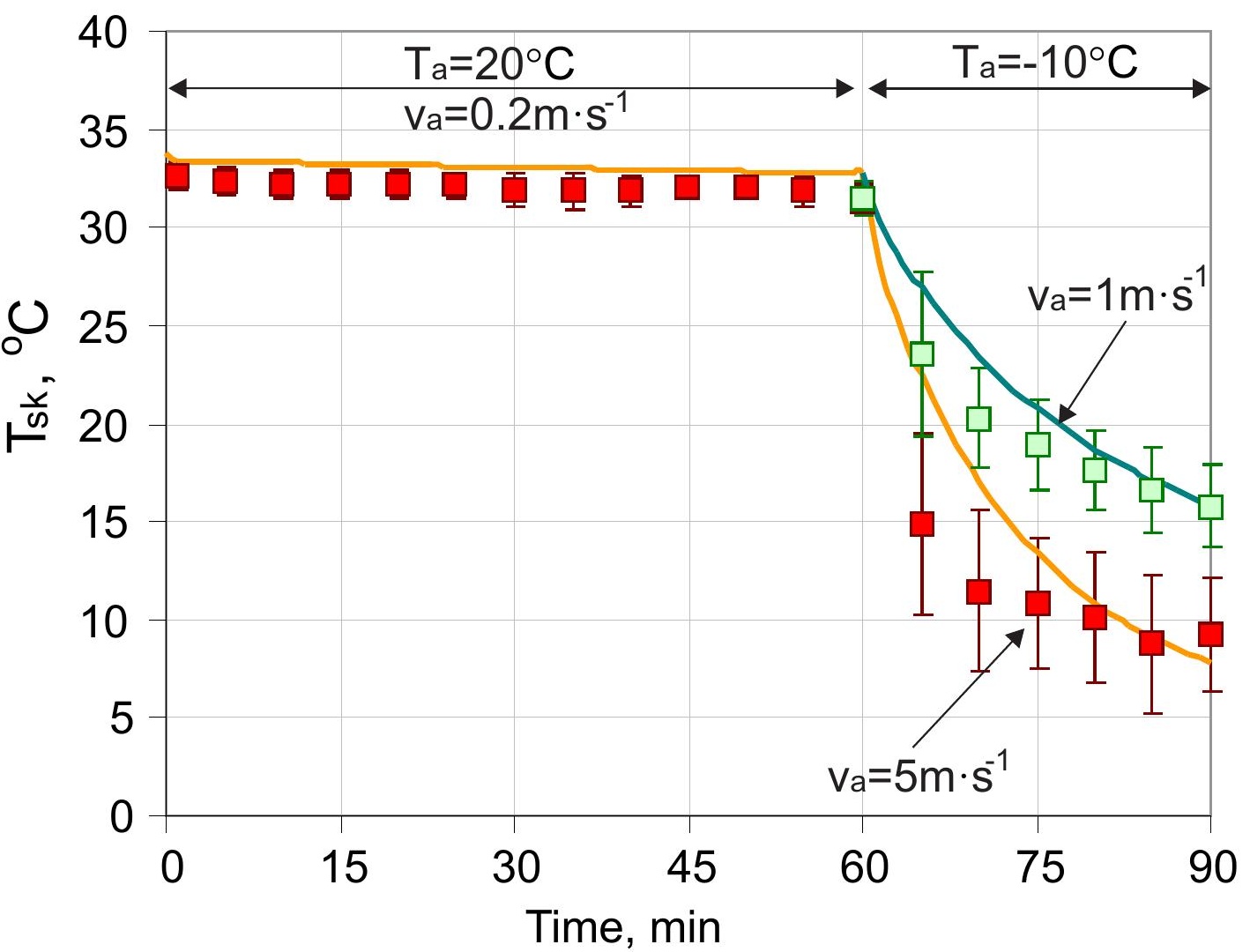

experiment
- simulation

$\square$ experiment

simulation for $1 \mathrm{~m} \cdot \mathrm{s}^{-1}$ 

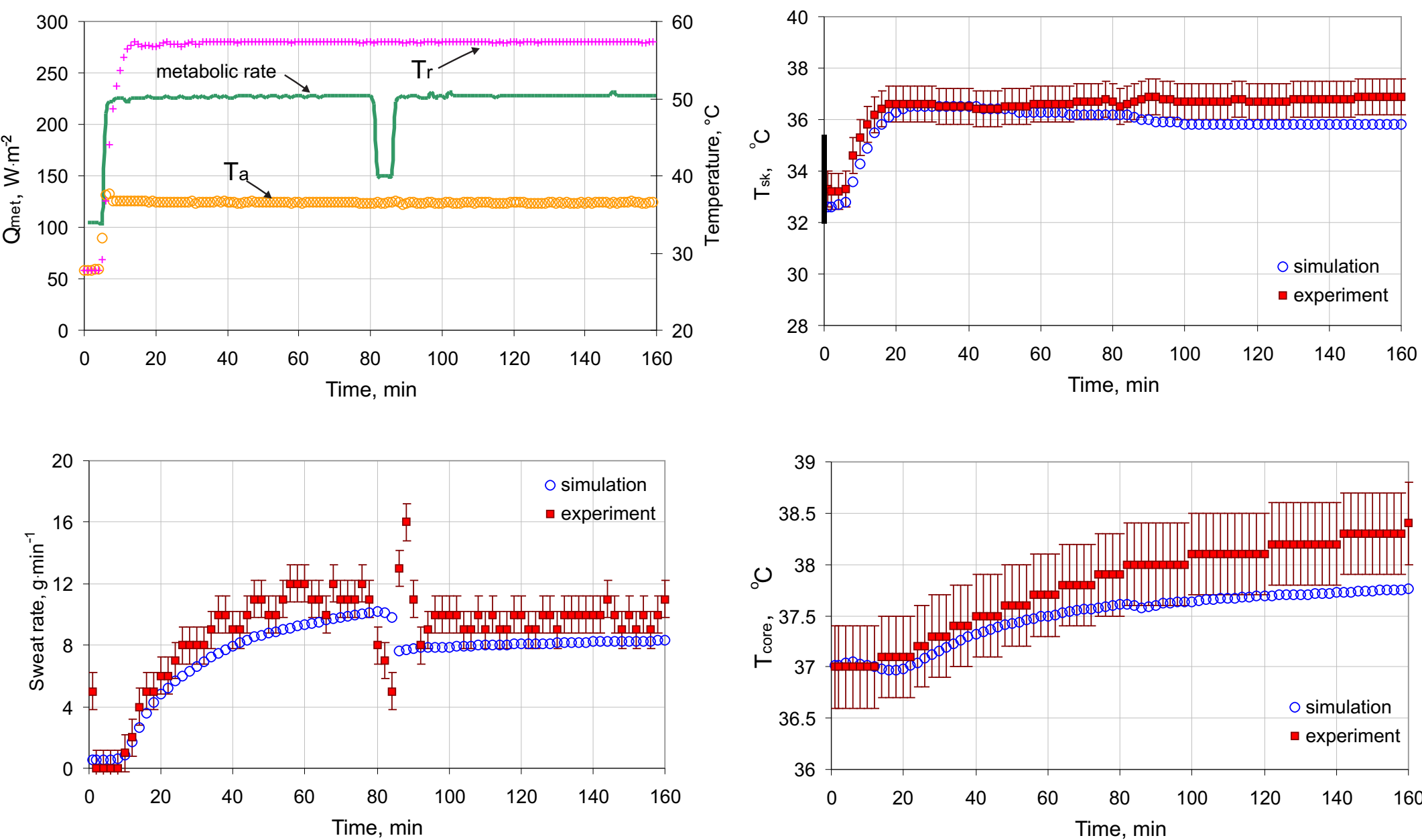

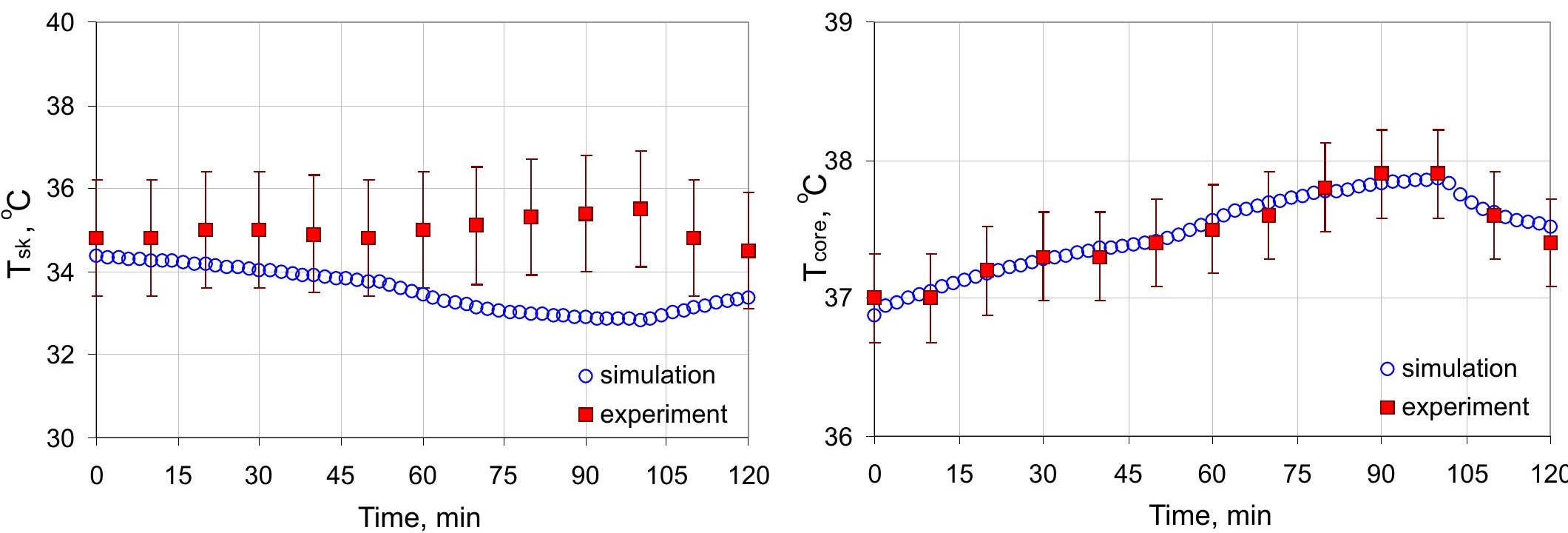

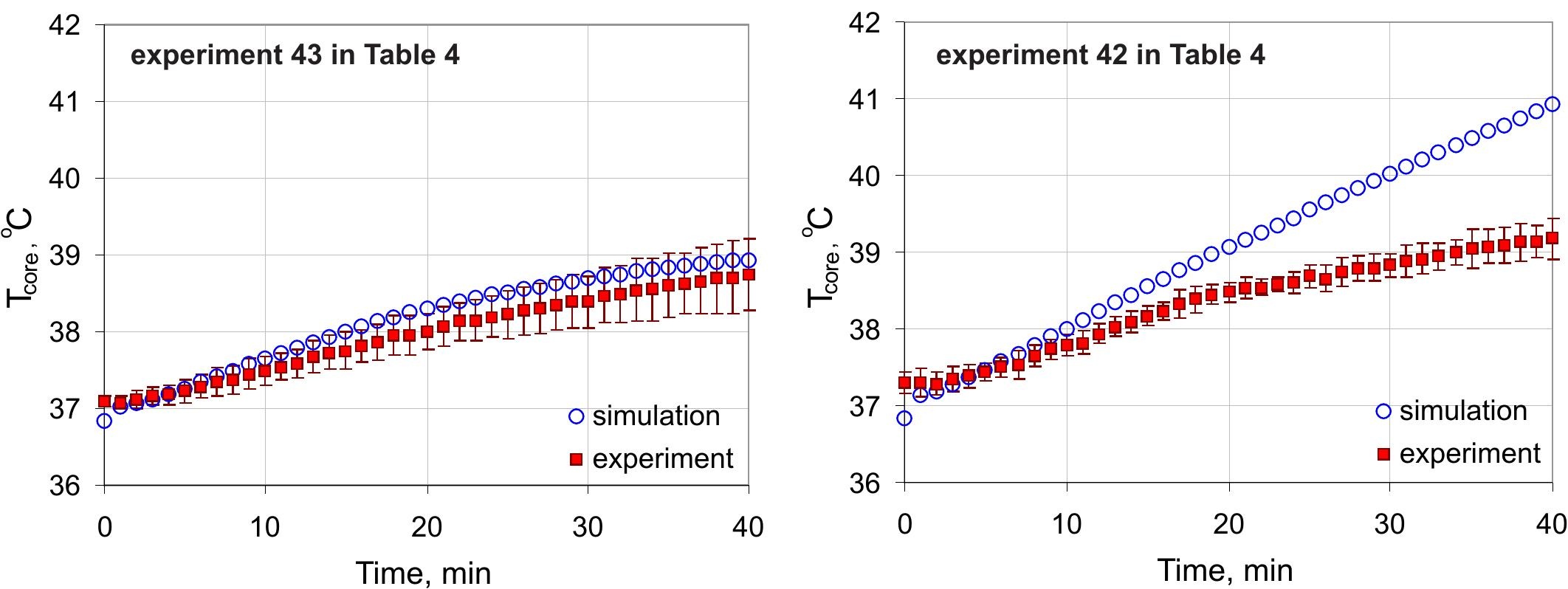


\begin{tabular}{|c|c|c|c|c|c|c|c|c|c|c|c|c|c|c|c|}
\hline \multirow{3}{*}{$\begin{array}{l}\text { Tab } \\
\text { No. }\end{array}$} & \multirow{2}{*}{$\begin{array}{l}\text { le4 } \\
\text { Duration }\end{array}$} & \multicolumn{5}{|c|}{ Environmental parameters } & \multicolumn{2}{|c|}{ Subjects } & & & & & & & \\
\hline & & Air temp. & \begin{tabular}{|c|} 
Radiant \\
temp.
\end{tabular} & \begin{tabular}{|l|} 
Relative \\
humidity \\
\end{tabular} & \begin{tabular}{|c|} 
Air \\
velocity
\end{tabular} & $\begin{array}{c}\text { Solar } \\
\text { radiation }\end{array}$ & $\begin{array}{l}\text { Metabolic } \\
\text { rate }\end{array}$ & Number & RcI/Rt & Recl & Tsk & Tcore & Tsk & Tcore & Source of data \\
\hline & $\min$ & ${ }^{\circ} \mathrm{C}$ & ${ }^{\circ} \mathrm{C}$ & $\% / \mathrm{kPa}$ & $\mathrm{m} / \mathrm{s}$ & $\mathrm{W} / \mathrm{m}^{2}$ & met & \begin{tabular}{|c|} 
males/ \\
females \\
\end{tabular} & clo & $\mathrm{m}^{2} \mathrm{kPa} / \mathrm{W}$ & ${ }^{\circ} \mathrm{C}$ & ${ }^{\circ} \mathrm{C}$ & ${ }^{\circ} \mathrm{C}$ & ${ }^{\circ} \mathrm{C}$ & \\
\hline 1 & & 8 & - & $48 \%$ & 0.10 & 48 & 4.0 & $0 / 6$ & & & 0.64 & 0.31 & 0.31 & 0.03 & \\
\hline 2 & & 0 & - & $64 \%$ & 0.16 & 134 & 4.6 & $9 / 1$ & $1.40 / 1.83$ & 0.037 & 0.81 & 0.38 & -0.75 & -0.22 & \\
\hline 3 & & -4 & - & $77 \%$ & 0.17 & 138 & 4.9 & $1 / 2$ & & & 0.73 & 0.52 & 0.40 & -0.42 & \\
\hline 4 & & 6 & - & $61 \%$ & 0.09 & 67 & 1.5 & $0 / 9$ & & & 0.53 & 0.30 & 0.03 & 0.29 & \\
\hline 5 & & 0 & - & $63 \%$ & 0.18 & 140 & 1.9 & $10 / 0$ & $1.40 / 1.83$ & 0.037 & 0.50 & 0.18 & -0.05 & -0.04 & \\
\hline 7 & 180 & -13 & - & $61 \%$ & 21.1 & 55 & $5.3(2.5)$ & $1 / 0$ & $140 / 183$ & 0.037 & 1.47 & 0.75 & -1.02 & 0.17 & Joser Steran institute in \\
\hline 8 & & -3 & - & $77 \%$ & 21.2 & 65 & 3.8 & $6 / 0$ & $1.40 / 1.83$ & 0.031 & 2.23 & 0.28 & 2.08 & -0.16 & \\
\hline 9 & & 0 & - & $82 \%$ & 18.0 & 11 & 1.6 & $4 / 0$ & $191 / 231$ & 0064 & 0.43 & 0.26 & -0.26 & 0.24 & \\
\hline 10 & & -8 & - & $54 \%$ & 20.4 & 14 & 2.9 & $4 / 0$ & $1.91 / 2.31$ & 0.064 & 0.80 & 0.28 & 0.61 & -0.13 & \\
\hline 11 & & 22 & - & $71 \%$ & 0.30 & 57 & 4.3 & $6 / 0$ & & $0.024-$ & 2.58 & 0.85 & 2.45 & -0.48 & \\
\hline 12 & & 24 & - & $57 \%$ & 0.41 & 109 & 4.2 & $3 / 0$ & $0.84 / 1.28$ & 0.006 & 2.23 & 0.52 & 2.12 & -0.27 & \\
\hline & & & & & & & & & & & & & & & \\
\hline 13 & & & & - & $0.2 / 0.2$ & - & & $8 / 0$ & & & 0.39 & 0.17 & -0.09 & -0.12 & \\
\hline 14 & & $20 /-10$ & & - & $0.2 / 1.0$ & - & $1.0 / 1.2$ & $8 / 0$ & $1.2 / 1.88$ & 0.02 & 0.53 & 0.10 & 0.37 & -0.02 & Makinen, Gavhed et al. 2000 \\
\hline 15 & $60 / 30$ & & $\sim=\mathrm{Ta}_{a},{ }_{2}$ & - & $0.2 / 5.0$ & - & & $8 / 0$ & & & 0.66 & 0.14 & 0.45 & -0.06 & H Rintamäki Finnish Institute of \\
\hline 18 & & & & - & $0.2 / 5.0$ & - & & $8 / 0$ & & & 0.72 & 0.21 & -0.35 & -0.08 & \\
\hline & & & & & & & & & & & & & & & \\
\hline 19 & $50 / 50 / 30$ & 30 & $\sim=\mathrm{Ta}$ & $30 \%$ & 0.1 & - & $2.21 / 3.59 / 0.98$ & $11 / 0$ & 0.1 & 0.013 & 1.59 & 0.07 & 1.42 & -0.01 & $\begin{array}{l}\text { Chappuis, Pittet et al. } 1976 \text { in } \\
\text { Haslam and Parsons } 1988\end{array}$ \\
\hline & & & & & & & & & & & & & & & \\
\hline 20 & $45 / 45$ & 49.5 & $\sim=\mathrm{Ta}$ & $32 \%$ & 0.1 & - & $1.0 / 4.42$ & $5 / 0$ & 0.1 & 0.013 & 0.68 & 0.23 & 0.59 & -0.21 & $\begin{array}{l}\text { Kobayashi, Horvath et al. } 1980 \\
\text { in Haslam and Parsons } 1988 \\
\end{array}$ \\
\hline & & & & & & & & & & & & & & & \\
\hline 21 & 60/120/60 & $43 / 17 / 43$ & $\sim=\mathrm{Ta}$ & $30 \%$ & 0.12 & - & 1.0 & $3 / 0$ & 0.1 & 0.013 & 0.51 & 0.17 & -0.11 & 0.13 & Hardy and Stolwijk 1966 \\
\hline & & & & & & & & & & & & & & & \\
\hline 22 & 100 & 35 & $\sim=\mathrm{Ta}_{a} \quad \& \quad r$ & $50 \%$ & 10 & - & 3.75 & $10 / 0$ & 1.69 & 0.100 & - & 0.06 & - & -0.01 & Gonzalez Mclellan et al 1997 \\
\hline 23 & 100 & 30 & Tha & $50 \%$ & 1.0 & - & 4.02 & 1070 & 0.82 & 0.040 & - & 0.09 & - & 0.02 & 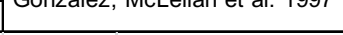 \\
\hline 24 & 120 & 40 & $\sim=\mathrm{Ta}$ & $40 \%$ & 02 & - & 3.35 & $100 / 0$ & 01 & 0013 & ( & 012 & - & 002 & Moran Shitzer et al 1998 \\
\hline & & & & & & & & & & & & & & & \\
\hline 25 & 170 & 28 & $\sim=\mathrm{Ta}$ & $50 \%$ & 0.1 & - & $1.0 / 3.9$ & $6 / 0$ & 0.1 & 0.013 & - & 0.10 & - & -0.07 & \\
\hline 26 & & $28 / 45$ & $\sim=\mathrm{Ta}$ & $2 \mathrm{kPa}$ & 0.1 & - & $11 / 24$ & $6 / 0$ & & & 1.20 & 0.19 & 1.03 & 0.14 & \\
\hline 27 & 180 & $23 / 50$ & $\sim=\mathrm{Ta}$ & $2 \mathrm{kPa}$ & 0.1 & - & $1.1 / 2.4$ & $6 / 0$ & 01 & 0.013 & 1.55 & 0.20 & 1.23 & 0.14 & \\
\hline 28 & 180 & 36 & $\sim=\mathrm{Ta}$ & $4 / 2 \mathrm{kPa}$ & 0.1 & - & $11 / 24$ & $6 / 0$ & 0.1 & 0.073 & 0.93 & 0.21 & 0.88 & 0.20 & \\
\hline 29 & & $23 / 50$ & $\sim=\mathrm{Ta}$ & $2 \mathrm{kPa}$ & 0.1 & - & $1.1 / 2.4$ & $6 / 0$ & & & 1.47 & 0.19 & 1.28 & 0.10 & \\
\hline 30 & 165 & $40 / 40$ & $\sim=\mathrm{Ta}$ & $65 \%$ & 0.1 & - & $\begin{array}{l}1.0 / 2.3 / \\
2.9 / 3.6\end{array}$ & $8 / 0$ & & & - & 0.15 & - & -0.09 & \\
\hline 33 & 166 & $40 / 25$ & $\sim=\mathrm{Ta}$ & $5 / 2 \mathrm{kPa}$ & 0.1 & - & $\begin{array}{l}1.0 / 2.3 / \\
2.9 / 3.7\end{array}$ & $8 / 0$ & & & - & 0.29 & - & -0.28 & \\
\hline 34 & 160 & $28 / 36$ & $28 / 36$ & $6 \mathrm{kPa}$ & 0.5 & - & $2.4 / 1.4$ & $5 / 0 \times 6$ & $0.1-0.6$ & 0.013 & 0.36 & 0.17 & 0.24 & 0.15 & \\
\hline 35 & 160 & 47 & 36 & $0.9 \mathrm{kPa}$ & 0.5 & - & $2.1 / 1.4$ & $5 / 0 \times 6$ & $0.1-0.6$ & 0.013 & 1.09 & 0.36 & 1.01 & 0.33 & \\
\hline 36 & 160 & 35 & 14 & $0.9 \mathrm{kPa}$ & 0.5 & - & $2.1 / 1.4$ & $5 / 0 \times 6$ & $0.1-0.6$ & 0.013 & 1.09 & 0.12 & 1.00 & 0.07 & \\
\hline 37 & 160 & 36 & 57 & $0.9 \mathrm{kPa}$ & 0.5 & - & $2.1 / 1.4$ & $5 / 0 \times 6$ & $0.1-0.6$ & 0.013 & 0.76 & 0.36 & 0.64 & 0.31 & \\
\hline & & & & & & & & & & & & & & & \\
\hline & & $\min / \max$ & $\min / \max$ & $\min / \max$ & $\min / \max$ & $\min / \max$ & $\min / \max$ & & in;out & in;out & & & & & \\
\hline 38 & 430 & $-3 / 22$ & $-11 / 22$ & $60 / 98 \%$ & $0.2 / 2.6$ & $0 / 128$ & $1.0 / 3.0$ & $1 / 0$ & $\begin{array}{l}0.87 / 1.37 \\
1.25 / 1.43\end{array}$ & $0.02 ; 0.04$ & 1.75 & 0.25 & -0.07 & 0.16 & \\
\hline 39 & 407 & $-4 / 21$ & $-11 / 21$ & 60/71\% & $0.2 / 10.5$ & $0 / 362$ & $0.8 / 4.7$ & $1 / 0$ & $\begin{array}{l}0.94 / 1.49 \\
1.07 / 1.21\end{array}$ & $0.02 ; 0.04$ & 2.78 & 0.23 & 1.46 & -0.14 & $\mathrm{vk}$ \\
\hline 40 & 347 & $-3 / 20$ & $-12 / 20$ & $60 / 96 \%$ & $0.2 / 2.4$ & $0 / 55$ & $0.8 / 4.0$ & $1 / 0$ & $\begin{array}{l}0.92 / 1.46 \\
1.22 / 1.40\end{array}$ & $0.02 ; 0.04$ & 2.05 & 0.18 & 1.20 & 0.06 & Poland \\
\hline 41 & 460 & $-7 / 20$ & $-11 / 22$ & $42 / 60 \%$ & $0.2 / 2.8$ & $0 / 411$ & $1.0 / 4.7$ & $1 / 0$ & $\begin{array}{l}0.92 / 1.45 \\
1.24 / 1.41\end{array}$ & $0.02 ; 0.04$ & 1.44 & 0.20 & 0.34 & -0.14 & \\
\hline & & & & & & & & & & & & & & & \\
\hline 42 & 40 & 28 & 28 & $50 \%$ & 328 & - & 12.1 & $6 / 0$ & $0.04 / 0.74$ & & 2.32 & 0.90 & 1.90 & -0.68 & \\
\hline 43 & 40 & 28 & 28 & $50 \%$ & 3.28 & - & 9.2 & $7 / 0$ & $0.04 / 0.74$ & 0.001 & 0.86 & 0.23 & 0.54 & -0.19 & Jack 2010 \\
\hline 44 & 40 & 35 & 35 & $40 \%$ & 2.85 & - & 8.1 & $7 / 0$ & $0.04 / 0.74$ & 0.001 & 1.17 & 0.72 & 0.85 & -0.72 & \\
\hline 45 & & & & & & & & & & & & & & & OPanon \\
\hline 45 & 70 & 30 & $\sim=\mathrm{Ta}$ & $70 \%$ & $0.3 / 0.7$ & - & $1.5 / 8.2$ & 8 & 0.1 & 0.013 & 2.59 & 0.24 & 2.22 & 0.21 & Daanen, van Es et al. 2006 \\
\hline 46 & & & & & & & & & & & & & & & \\
\hline 46 & & 30 & $\sim=\mathrm{Ta}_{a}$ & $20 \%$ & & & $\sim 1.3 / \sim 4.8$ & $1 / 1$ & & & 0.83 & 0.64 & 0.32 & 0.62 & \\
\hline 47 & & & $-1 \mathrm{~d}$ & & & & $\sim 1.3 / \sim 1.8$ & $1 / 1$ & 023 & 001 & 2.02 & 0.62 & -0.76 & 0.47 & \\
\hline 48 & & 30 & & $80 \%$ & & & $\sim 1.3 / \sim 4.8$ & $1 / 1$ & 0.23 & 0.07 & 1.13 & 0.69 & 0.51 & 0.65 & \\
\hline 49 & & 30 & $\sim=1 \mathrm{a}$ & $80 \%$ & & & $\sim 1.3 / \sim 1.8$ & $1 / 1$ & & & 1.24 & 0.86 & 0.34 & 0.79 & \\
\hline 50 & 120 & 20 & $\sim=\mathrm{Ta}$ & $50 \%$ & 0.3 & - & $\sim 1.3 / \sim 4.8$ & $1 / 1$ & & & 0.93 & 0.64 & 0.35 & 0.63 & \\
\hline 51 & 120 & 20 & $\sim=1 \mathrm{a}$ & $50 \%$ & 0.3 & - & $\sim 1.3 / \sim 1.8$ & $1 / 1$ & & & 2.21 & 0.72 & -1.15 & -0.31 & \\
\hline 52 & & 5 & $\sim=T_{a}$ & $50 \%$ & & & $\sim 1.3 / \sim 4.8$ & $2 / 0$ & 073 & 002 & 1.08 & 0.30 & -0.98 & 0.28 & TNO Defence Security and, \\
\hline 53 & & 5 & $\sim=1 \mathrm{a}$ & $50 \%$ & & & $\sim 1.3 / \sim 1.8$ & $1 / 1$ & 0.73 & 0.02 & 2.01 & 0.32 & -1.90 & 0.19 & Defence, Securty and \\
\hline 54 & & -5 & & $50 \%$ & & & $\sim 1.3 / \sim 4.8$ & $2 / 0$ & & & 3.50 & 0.42 & -3.44 & 0.22 & \\
\hline 55 & & -5 & $\sim=\mathrm{Ta}$ & $50 \%$ & & & $\begin{array}{l}\sim 1.3 / \sim 1.8 \\
\end{array}$ & $2 / 0$ & & & 6.59 & 0.44 & -6.56 & 0.29 & \\
\hline 56 & 75 & 10 & $\sim=\mathrm{Ta}$ & $60 \%$ & $0.3 / 1.0$ & - & $3.8 / 5.2 / 1.2$ & $12 / 0 \times 3$ & 1.0 & 0.02 & 0.58 & 0.28 & -0.20 & -0.07 & \\
\hline 57 & 56 & & & & & & $1.3 / 7.4 / 9.4$ & $0 / 1$ & & & 0.55 & 0.44 & 0.04 & -0.19 & \\
\hline 58 & 56 & 30 & $\sim=\mathrm{Ta}$ & $80 \%$ & 0.3 & 600 & $1.3 / 7.2 / 9.2$ & $0 / 1$ & 0.12 & 0.01 & 0.60 & 0.46 & 0.13 & 0.36 & \\
\hline
\end{tabular}




\begin{tabular}{|c|c|c|c|c|c|c|c|c|c|c|c|c|c|c|c|c|c|c|c|c|c|c|c|c|c|}
\hline \multirow{3}{*}{ No. } & \multirow{3}{*}{ Source of data } & \multirow{3}{*}{$\begin{array}{l}\text { Experiment } \\
\text { name }\end{array}$} & \multirow[b]{2}{*}{ Duration } & \multicolumn{6}{|c|}{ Environmental parameters } & \multicolumn{4}{|c|}{ Subjects } & \multicolumn{3}{|c|}{ Clothing } & \multicolumn{3}{|c|}{ rmsd } & \multicolumn{3}{|c|}{ Bias } & \multicolumn{3}{|c|}{$\mathrm{n}$} \\
\hline & & & & Type & Air temp. & \begin{tabular}{|c} 
Radiant \\
temp.
\end{tabular} & \begin{tabular}{|l|}
$\begin{array}{c}\text { Relative } \\
\text { humidity }\end{array}$ \\
\end{tabular} & \begin{tabular}{|c|c} 
Air \\
velocity
\end{tabular} & \begin{tabular}{|c|} 
Solar \\
radiation
\end{tabular} & $\begin{array}{c}\text { Activity } \\
\text { type }\end{array}$ & \begin{tabular}{|c}
$\begin{array}{c}\text { Metabolic } \\
\text { rate }\end{array}$ \\
\end{tabular} & \begin{tabular}{|c|}
$\begin{array}{c}\text { External } \\
\text { work }\end{array}$ \\
\end{tabular} & Number & Avaliability & Rcl/Rt & Recl & Tsk & Tcore & $\begin{array}{c}\text { Sweat } \\
\text { rate }\end{array}$ & Tsk & Tcore & $\begin{array}{c}\text { Sweat } \\
\text { rate }\end{array}$ & Tsk & Tcore & $\begin{array}{c}\text { Sweat } \\
\text { rate }\end{array}$ \\
\hline & & & $\min$ & $\begin{array}{c}\text { field/ } \\
\text { chamber }\end{array}$ & ${ }^{\circ} \mathrm{C}$ & ${ }^{\circ} \mathrm{C}$ & $\%$ & $\mathrm{~m} / \mathrm{s}$ & $\mathrm{W} / \mathrm{m}^{2}$ & - & met & met & \begin{tabular}{|c|}
$\begin{array}{c}\text { males/ } \\
\text { females }\end{array}$ \\
\end{tabular} & $\begin{array}{l}\text { measured/ } \\
\text { estimated }\end{array}$ & clo & $\mathrm{m}^{2} \mathrm{kPa} / \mathrm{W}$ & ${ }^{\circ} \mathrm{C}$ & ${ }^{\circ} \mathrm{C}$ & $\mathrm{g} / \mathrm{min}$ & ${ }^{\circ} \mathrm{C}$ & ${ }^{\circ} \mathrm{C}$ & $g / \min$ & - & - & - \\
\hline \multirow{10}{*}{4} & \multirow{10}{*}{$\begin{array}{l}\text { unpublished from } \\
\text { I.Mekjavic, Josef } \\
\text { Stefan Institute in } \\
\text { Ljubljana, Slovenia }\end{array}$} & & \multirow{10}{*}{180} & \multirow{10}{*}{ field } & 8 & & 48 & 0.10 & 48 & \multirow{3}{*}{ hiking } & 40 & 0.01 & $0 / 6$ & \multirow{3}{*}{ estimated } & \multirow{3}{*}{ 1.40/1.83 } & \multirow{3}{*}{0.037} & 0.64 & 0.31 & & 0.31 & 0.03 & & 37 & 36 & \\
\hline & & \begin{tabular}{|l|l|} 
Pokjuka1 \\
\end{tabular} & & & 0 & - & 64 & 0.16 & 134 & & 4.6 & -0.04 & $9 / 1$ & & & & 0.04 & 0.38 & - & -0.75 & $\begin{array}{r}0.00 \\
-0.22 \\
\end{array}-10$ & & 37 & 37 & - \\
\hline & & & & & -4 & - & 77 & 0.17 & 138 & & 4.9 & -0.02 & $1 / 2$ & & & & 0.73 & 0.52 & - & 0.40 & -0.42 & - & 37 & 35 & - \\
\hline & & \begin{tabular}{|l|} 
Pokjjuka1 \\
\end{tabular} & & & 6 & $\therefore$ & $\frac{61}{63}$ & $\begin{array}{l}0.09 \\
0.18\end{array}$ & $\frac{67}{140}$ & walk/stand & $\frac{1.5}{1.9}$ & - & $\frac{0,9}{10 / 0}$ & \multirow{2}{*}{ estimated } & \multirow{3}{*}{ 1.40/1.83 } & \multirow{3}{*}{0.037} & 0.53 & 0.30 & $\therefore$ & $\frac{0.03}{-0.05}$ & $\frac{0.29}{0.04}$ & 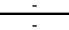 & 37 & 37 & - \\
\hline & & & & & -6 & & 88 & 0.30 & 149 & & 1.7 & & $2 / 0$ & & & & 0.91 & 0.38 & & -0.57 & 0.27 & & $\frac{\pi}{36}$ & $\frac{12}{32}$ & \\
\hline & & Pokkiuka2 & & & -13 & - & 61 & 21.1 & 55 & hiking & $5.3(2.5)$ & -0.07 & $1 / 0$ & \multirow{2}{*}{ measured } & & & 1.47 & 0.75 & - & -1.02 & 0.17 & - & $\frac{30}{37}$ & $\frac{32}{37}$ & $\therefore$ \\
\hline & & Fonjunate & & & -3 & - & 77 & 21.2 & 65 & niking & 3.8 & \begin{tabular}{l|l}
-0.08 \\
\end{tabular} & $6 / 6$ & & \multirow{2}{*}{\begin{tabular}{|l|l}
$1.40 / 1.83$ \\
$1.91 / 2.31$
\end{tabular}} & 0.037 & 2.23 & 0.28 & & 208 & -0.16 & & $\frac{37}{37}$ & 37 & - \\
\hline & & \begin{tabular}{|l|} 
Pokjjuka2 \\
\end{tabular} & & & 0 & 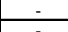 & $\frac{82}{54}$ & 18.0 & $\frac{11}{14}$ & walk/stand & 1.6 & & $4 / 0$ & measured & & 0.064 & 0.43 & 0.26 & - & -0.26 & 0.24 & - & 37 & 37 & - \\
\hline & & Ankaran & & & 22 & 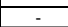 & $\frac{74}{71}$ & $\frac{2.4}{0.30}$ & $\frac{14}{57}$ & hikina & $\begin{array}{l}2.5 \\
.3\end{array}$ & -0.01 & $\frac{40}{6 / 0}$ & meosured & \multirow{2}{*}{$0.84 / 1.28$} & 0.024 & 2.00 & 0.20 & - & 2.01 & $\begin{array}{r}-0.15 \\
-0.48 \\
\end{array}$ & - & 37 & 37 & - \\
\hline & & Ankarann & & & 24 & - & 57 & 0.41 & 109 & hiking & 4.2 & -0.01 & $3 / 0$ & measured & & 0.006 & 2.23 & 0.52 & - & 2.12 & -0.27 & - & 27 & 37 & - \\
\hline \multirow{4}{*}{\begin{tabular}{|c|}
13 \\
14 \\
15 \\
16 \\
17 \\
18 \\
\end{tabular}} & Makinen, Ga & & & & & & & & - & & 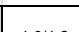 & & 2 & & & & 0.39 & & 5 & -0.09 & -0.12 & - & & & - \\
\hline & $\begin{array}{l}\text { al. } 2000 \text { and } \\
\text { unpublished from }\end{array}$ & cld wind & 60130 & chamber & $20 \mid-10$ & $-T_{0}$ & - & \begin{tabular}{|l|}
0.211 .0 \\
0.215 .0 \\
\end{tabular} & $\therefore$ & - recl/stand & 1.0/1.2. & - & $\frac{810}{810}$ & measured & 1.211 .88 & 0.02 & $\begin{array}{l}0.53 \\
0.66 \\
\end{array}$ & $\begin{array}{l}0.10 \\
0.14\end{array}$ & $\therefore$ & 0.37 & $\frac{-0.02}{-0.06}$ & - & 10 & 10 & - \\
\hline & H.Rintamäki, Finnish & cold wind & $\mid$\begin{tabular}{|l|l|l|}
$\mid 60 / 30$ \\
\end{tabular} & chamber & $-5 / 10$ & $\sim=\mathrm{Ta}$ & - & \begin{tabular}{|l|l|}
0.210 .2 \\
02112
\end{tabular} & - & rec/stand & 1012 & 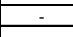 & $8 / 0$ & measured & 188 & 802 & \begin{tabular}{|l|l|}
0.78 \\
0.53
\end{tabular} & 0.15 & 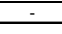 & -0.74 & $\begin{array}{ll}-0.02 \\
02\end{array}$ & 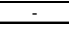 & 19 & 19 & - \\
\hline & $\begin{array}{l}\text { Institute of } \\
\text { Occupational Health. }\end{array}$ & & & & & & - & \begin{tabular}{|l|}
0.215 .0 \\
0.215 .0
\end{tabular} & - & 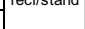 & & & $8 / 0$ & measured & & & $\begin{array}{l}0.53 \\
0.72 \\
\end{array}$ & 0.11 & $\therefore$ & $\frac{-0.36}{-0.35}$ & $\begin{array}{l}-0.02 \\
-0.08 \\
\end{array}$ & - & & & - \\
\hline
\end{tabular}

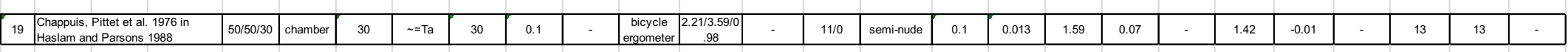

\begin{tabular}{|l|l|l|l|l|l|l|l|l|l|l|l|l|l|l|l|l|l|l|l|l|l|l|l|l|}
\hline 20 & $\begin{array}{l}\text { Kobayashi, Hovath et al } 1.1980 \text { in } \\
\text { Haslam and Parsons } 1988\end{array}$ & $45 / 45$ & chamber & 49.5 & $\sim=$ Ta & 32 & 0.1 & - & $\begin{array}{c}\text { bicycle } \\
\text { ergometer }\end{array}$ & $1.0 / 4.42$ & - & $5 / 0$ & semi-nude & 0.1 & 0.013 & 0.68 & 0.23 & - & 0.59 & -0.21 & - & 18 & 19 & - \\
\hline
\end{tabular}

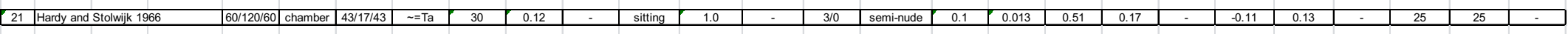

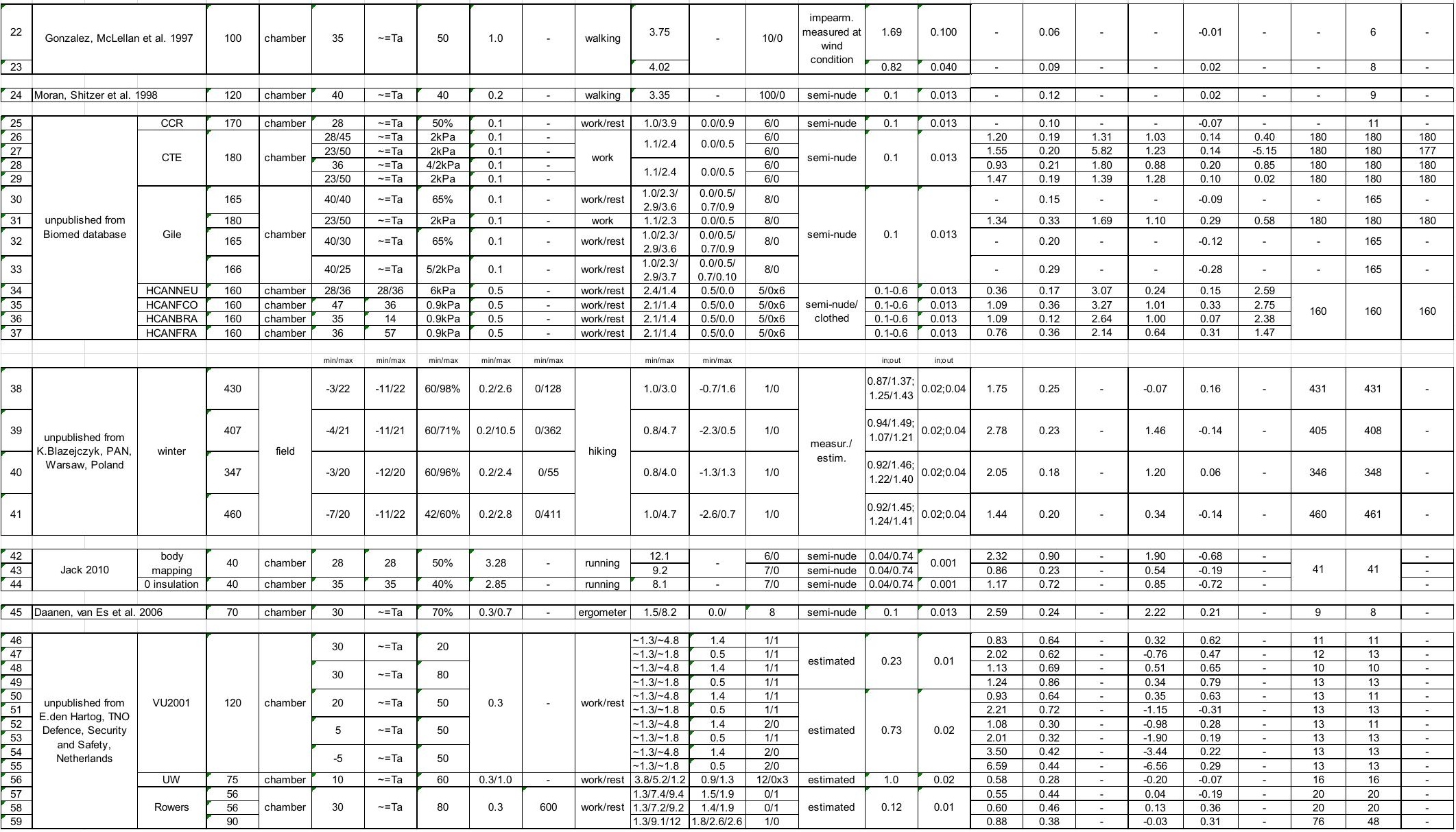



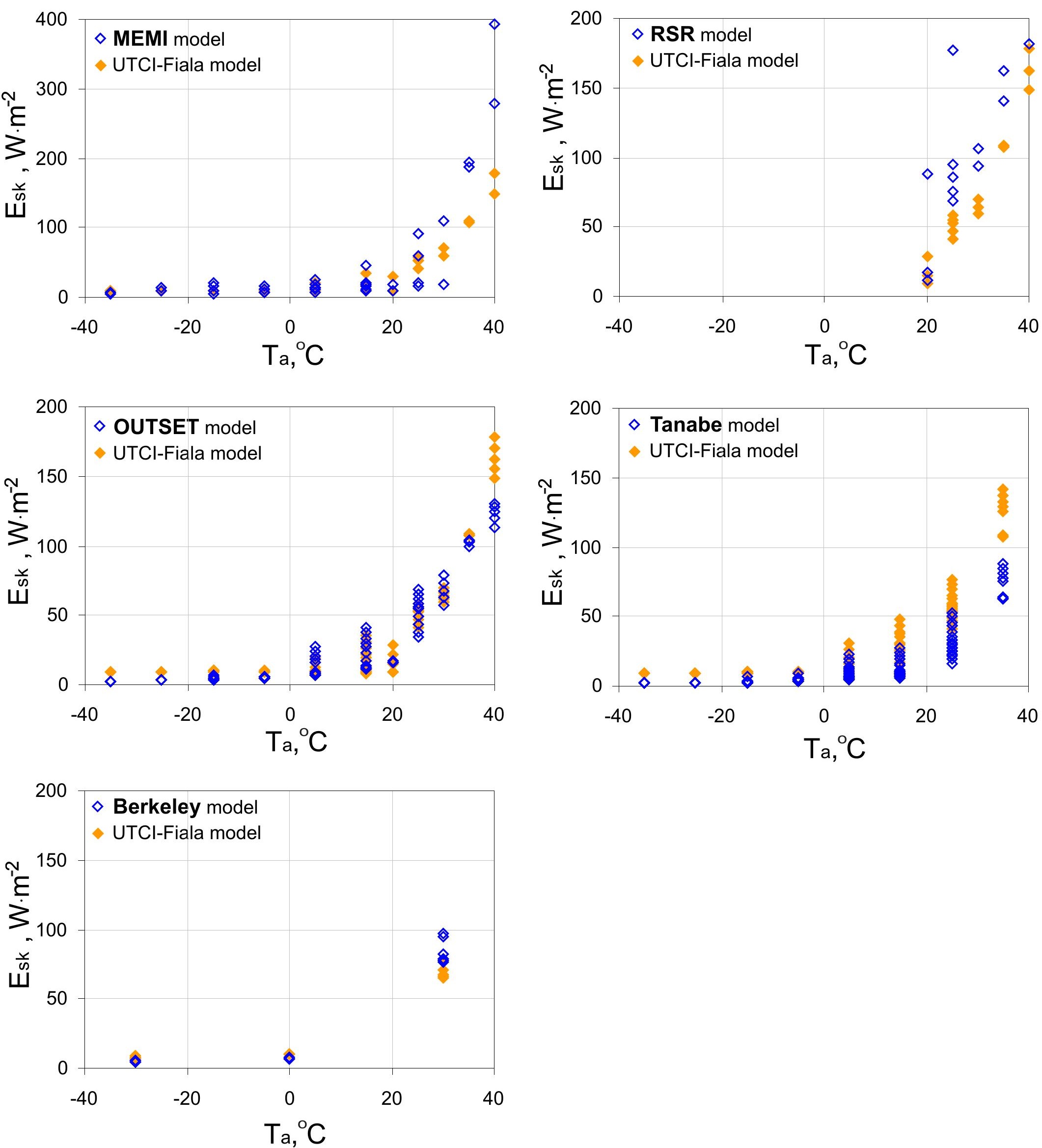